\title{
Improving the corrosion properties of amorphous Ni-P thin films using different additives
}

\author{
A. Bahramian, M. Eyraud*, F. Vacandio, P. Knauth \\ Aix Marseille Univ, CNRS, Madirel, UMR 7246, Electrochemistry of Materials Group, Campus St Jérôme, 13397 \\ Marseille, France \\ * Corresponding author: marielle.eyraud@univ-amu.fr \\ Highlights \\ - Effects of various additives on the corrosion resistance of Ni-P films is studied. \\ - Thinner, more uniform, and smoother Ni-P thin films are formed with additives. \\ - Excellent improvement of the corrosion resistance is observed.
}

\begin{abstract}
Ni-P amorphous coatings are considered as important engineering alloys. In this paper, the effects of various additives on the properties of Ni-P thin films were investigated, including saccharine, glycine, pyridinium propyl sulfonate, coumarin, sodium citrate, and cerium sulfate. Potentiodynamic polarization and electrochemical impedance spectroscopy tests, scanning electron microscopy, X-ray fluorescence and diffraction, and atomic force microscopy were employed to study the properties of the samples. It was found that a proper concentration of these additives, except saccharine, noticeably improved the corrosion resistance, especially at high potentials (about $25 \%$ increase in instantaneous corrosion efficiency and about $300 \%$ in corrosion efficiency at high potentials) and decreased the surface roughness (by about 10 to $55 \%$ ) of Ni-P thin films. Thinner, more uniform, and less porous coatings were formed in the presence of additives. Except saccharine, all the additives enhanced the P content of Ni-P films, which thus kept their amorphous structure; saccharine highly suppressed the incorporation of $\mathrm{P}$ inside the $\mathrm{Ni}$ lattice and a mixed amorphous-crystalline structure was stabilized.
\end{abstract}

Keywords: Ni-P coatings, additives, electrodeposition, corrosion efficiency

\section{1- Introduction}

$\mathrm{Cu}$ and its alloys, in bulk or electrodeposited form, are considered important materials in industry due to their high electrical and thermal conductivity, mechanical workability, low chemical reactivity, and atmospheric corrosion resistance. Such properties make these materials suitable for many applications, including electronics, telecommunications, and heat exchangers. However, their poor corrosion properties, especially in the presence of aggressive ions like chlorides, limit their usage [1-4]. As a result, there are several studies related to the 
improvement of the corrosion properties of $\mathrm{Cu}$ and its alloys using different approaches including protective coatings [2,5] and corrosion inhibitors [1,6-8].

The preparation of thin film coatings using electrochemical methods is attractive due to their simplicity, the opportunity to work generally at ambient temperature, the uniform and controllable deposition rate, the possibility to form multilayers, the ability to coat large surfaces in almost any shape and geometry, and the low cost $[9,10]$. Electrodeposition is one of the most frequently used methods, which can promote the appearance, extend the lifetime, and improve the performance of the substrate by producing metallic (metals, alloys, composites) single or multi-layers through a highly controllable procedure [11]. Compared to other methods of forming thin films (such as physical deposition processes [12]), electrochemical techniques are more economical, and thus, they are widely used to cover a wide range of applications like electrical contacts, corrosion and wear resistance, decorative purposes, photovoltaic devices, and so on $[9,13]$. The electrodeposition of iron group metals $(\mathrm{Ni}, \mathrm{Co}$, and $\mathrm{Fe})$ in particular attracts interest due to their unique magnetic and thermophysical properties [5].

Ni-P coatings are considered important engineering alloys due to their interesting combination of properties, i.e. good corrosion and wear resistance, good solderability, high electrical conductivity, smooth and uniform surface morphology, low friction coefficient, electrocatalytic activity, and paramagnetic characteristics; they can be obtained through simple electrochemical methods [5,14-17]. These alloys can be also employed as the under-layer for other top coatings [18]; they are especially important in microelectronics due to their usage as diffusion barriers between copper and gold and for the corrosion protection of contacts [5]. $\mathrm{Cu} / \mathrm{Ni}$ $\mathrm{P} / \mathrm{Au}$ multi-layer films are used in electronics and microelectronics in applications such as switches, relays, circuit breakers, SIM cards, electrical contacts, and contactors, because they present a combination of high electrical conductivity, corrosion resistance, and wear resistance [19-22]. Compared to Ni coatings, Ni-P films present a bright, shiny, and smooth look [15], and are less susceptible to oxidation [23]. It is well known that phosphorus cannot be electrodeposited as a pure phase, but its co-deposition with iron group metals is possible. The electrodeposition mechanism of Ni-P coatings is based on the reduction of $\mathrm{Ni}$ ions and $\mathrm{PO}_{3}{ }^{3-}$ ions. In fact, $\mathrm{Ni}^{2+}$ ions are reduced on active surface sites of the cathode and then diffuse to a proper site of the lattice. The co-deposited $\mathrm{P}$ atoms hinder the Ni diffusion, and thus impede crystalite nucleiation. Therefore, the amount of $\mathrm{P}$ in the alloy affects its crystallographic structure; increasing the $\mathrm{P}$ content changes the microstructure from 
crystalline to nano-crystalline and finally to an amorphous state. According to the literature, there is not a specific content but a range of $\mathrm{P}$ contents for the crystalline to amorphous transition of Ni-P coatings [15]. However, coatings with P contents higher than $8 \%$ present usually an amorphous structure [14]. Given that the $\mathrm{P}$ content largely determines the properties of Ni-P coatings shows the importance of the chemical composition of the electrodeposition bath. it is well known that introducing even a small amount of certain compounds as additives to the electrolyte significantly affects the properties and appearance of deposits [24]. The refinement of the microstructure, with a decrease of the internal stress and the surface roughness, an increase of the brightness, and the improvement of the corrosion resistance and mechanical properties of the coatings are some of the reported benefits of additives $[11,16,17,23,25-29]$. Organic compounds are the most commonly used additives, and they are called carriers, brighteners, complexing agents, leveling agents, and so on, based on their purpose; carriers are those that are added to refine the grain size and increase the luster [25]. There are several studies regarding the effects of using saccharine [23], glycine [26], coumarin [29], sodium citrate [30] as organic additives. Moreover, similar benefits have been also reported by adding rare metal salts to the deposition electrolyte [31]. Based on these studies, utilizing even small quantities of these compounds can highly enhance the properties of the obtained coatings, and thus, their usage is highly recommended.

There are several studies regarding the improvement of the corrosion resistance of Ni-P films, including the preparation of ternary alloys and composite coatings. Implementing additives are not as challenging as forming ternary alloys [32] and there is no concern about their agglomeration as it occurs for nano-particles [33]. Therefore, additives are easier to use, more economical, and more practical for the mentioned purpose. To the best of our knowledge, among all the published papers related to the utilization of additives, there is no study regarding the comparison of the effects of different additives on the corrosion resistance of Ni-P coatings on copper. Moreover, almost all studies have used high deposition times, and thus, investigated the effects of additives on thick layers. As a result, there is no work about the effect of several additives on the properties of thin Ni-P films and finding their optimum concentration.

In this paper, the effect of different additives has been investigated and compared for thin Ni-P layers formed on copper, which is especially interesting for microelectronics. The additives include saccharine that is the most commonly used carrier, brightener, and stress reducing agent; coumarin as brightener; pyridinium 
ions as auxiliary brightener [25]; glycine that is the smallest amino acid [26] as complexing and buffering agent [34]; sodium citrate used as complexing, buffering and leveling agent [11]; and cerium sulfate as a rare metal salt [31]. However, it should be noted that while a combination of additives is usually applied for the deposition of single ions, e.g. $\mathrm{Cu}$ [24], Ni [25], their synergistic effect [11] could limit their influence on the electrodeposition of Ni-P alloys. Therefore, we present only the effect of individual mentioned additives in the following.

\section{2- Experimental procedure}

Industrially available smooth $\mathrm{Cu}$ films were used as the substrate for Ni-P electrodeposited coatings. All samples underwent a chemical pretreatment: $30 \mathrm{~s}$ in a diluted basic solution $\left(1 \mathrm{~mL}\right.$ of $30 \% \mathrm{NH}_{4} \mathrm{OH}$ solution in $200 \mathrm{~mL}$ of demineralized water), $30 \mathrm{~s}$ in demineralized water, and $30 \mathrm{~s}$ in a $10 \% \mathrm{H}_{2} \mathrm{SO}_{4}$ solution to eliminate oxides, if there are any, and clean the surface before the deposition process.

A common electrodeposition bath, containing $190 \mathrm{~g} / \mathrm{L} \mathrm{NiSO} 4.6 \mathrm{H}_{2} \mathrm{O}+10 \mathrm{~g} / \mathrm{L}$ $\mathrm{NiCl}_{2} .6 \mathrm{H}_{2} \mathrm{O}$ (as Ni source), $8 \mathrm{~g} / \mathrm{L} \mathrm{H}_{3} \mathrm{PO}_{3}$ (as P source), $5 \mathrm{~mL} / \mathrm{L} \mathrm{H}_{3} \mathrm{PO}_{4}$ (to enhance the stability of $\mathrm{H}_{3} \mathrm{PO}_{3}$ ), and $16 \mathrm{~g} / \mathrm{L} \mathrm{H}_{3} \mathrm{BO}_{3}$ (as buffering agent) has been employed as the main bath to form the Ni-P coatings. 5 different concentrations of additives were prepared: saccharine and glycine $(0.1,0.5,1,2.5$, and $5 \mathrm{~g} / \mathrm{L})$, coumarin $(5,10$, $50,100$, and $250 \mathrm{mg} / \mathrm{L})$, pyridinium propyl sulfonate $(0.1,0.5,1,2$, and $4 \mathrm{~g} / \mathrm{L}$ ), sodium citrate $(4,8,12,16$, and $20 \mathrm{~g} / \mathrm{L})$, and cerium sulfate $(4,8,12,20$, and 30 $\mathrm{mg} / \mathrm{L})$. All the chemicals were provided by Sigma-Aldrich with high purity. They were added to the main bath to investigate their effects on the corrosion resistance of Ni-P coatings. The $\mathrm{pH}$ of the deposition electrolyte, in the absence and presence of additives, was 1 . All the samples are named using the first three letters of their respective additives and their concentration; i.e. Cou. $10 \mathrm{~m}$ represents the Ni-P coating formed in the presence of $10 \mathrm{mg} / \mathrm{L}$ of coumarin as the additive.

A 3-electrode setup cell was used for the coating process: the pretreated $\mathrm{Cu}$ films was the cathode or working electrode, a Pt electrode functioned as the anode or counter electrode, and $\mathrm{Ag} / \mathrm{AgCl}(\mathrm{KCl}$ saturated) performed as the reference electrode. All samples were coated at $60^{\circ} \mathrm{C}$ using a Solartron 1287 potentiostat at a constant potential of $-1 \mathrm{~V}$ vs. the reference electrode for 7 minutes, while the solution was stirred at a speed of $650 \mathrm{rpm}$. These conditions were employed after preliminary experiments (not presented here) to obtain bright, homogeneous and compact Ni-P films. The mass of the coatings was measured by subtracting the mass after and 
before the deposition process using a precision scale $\left( \pm 10^{-4} \mathrm{~g}\right)$. Three coatings were made for each condition.

Electrochemical impedance spectroscopy (EIS) and potentiodynamic polarization tests were employed to determine the corrosion properties of the obtained Ni-P films in the absence and presence of different concentrations of the mentioned additives. The same setup as for the coating process was used for the corrosion measurements; the coated samples acted as the working electrode. All tests were performed using a PARSTAT 2273 potentiostat, which was operated by the PowerSuit software after $1 \mathrm{~h}$ immersion in a $3 \% \mathrm{NaCl}$ solution. The EIS measurements were done in a frequency range of $10 \mathrm{kHz}-10 \mathrm{mHz}$ with a voltage amplitude of $10 \mathrm{mV}$ (peak-topeak) versus the respective Open Circuit Potential (OCP). The Zview software was used to analyze the obtained EIS data. The potentiodynamic polarization experiments were carried out from $-300 \mathrm{mV}$ (vs. OCP) to $500 \mathrm{mV}$ (vs. reference electrode) at a scan rate of $0.5 \mathrm{mV} / \mathrm{s}$. The area exposed to the corrosive medium was measured after the tests and used to normalize the obtained corrosion data. Each test was repeated twice to be sure of its validity.

After evaluating the corrosion results, the best samples among each category were chosen for further characterization. A Siemens D5000 diffractometer was used to evaluate the structure of the selected samples. X-ray diffractometry (XRD) with $0.04^{\circ}$ step size over the $2 \theta$ range of $40-55^{\circ}$ was done using $\mathrm{Cu} \mathrm{K} \alpha$ radiation $(\lambda=$ $0.15406 \mathrm{~nm}$ ) generated at $40 \mathrm{kV}$ and $30 \mathrm{~mA}$. A scanning electron microscope (SEM) model Philips XL 30 ESEM equipped with an Energy dispersive spectroscopy (EDS) analyzer was used to investigate the surface morphology and chemical composition of the selected coatings. The thickness of the samples was measured at different locations of the samples using the X-ray fluorescence technique (Fischerscope XRAY XDV- $\mu$ ). A Digital Instruments Dimension 3100 atomic force microscope (AFM) was also employed for a more detailed examination of the morphology and to measure the roughness using Nova software.

\section{3- Results}

Figure 1 shows the effects of the additives on the current density during the electrodeposition process. As it can be seen, the current density decreases rapidly at the beginning of the coating procedure and then stays at a stationary value until the end of the process. Moreover, the addition of all chosen additives to the Ni-P electrodeposition bath led to lower current densities during the coating procedure. 
For example, the current is almost divided by 3 in the case of the addition of sodium citrate, and by 1.5 when cerium sulfate is added to the Ni-P bath. Therefore, even if only the water side reaction is impacted by the additives, the thickness of the Ni-P layers in presence of additives is assumed to be decreased as well. This assumption will be checked later by cross-sectional observations, gravimetric and X-ray fluorescence measurements.

Table 1 and Table 2 present the analyzed information from potentiodynamic polarization and EIS tests, respectively. Figure 2 depicts the surface of the samples before and after the corrosion tests. The curves for samples that were considered the best in each category are depicted in Figure 3 and

Figure 4. Based on the presented data and irrespective of the presence of additives, applying a Ni-P layer on $\mathrm{Cu}$ shifted the corrosion potential to more negative values and decreased the corrosion current density. The use of a proper amount of the tested additives improved the corrosion properties of Ni-P films, especially at high potentials.

Figure 7 shows the $\mathrm{X}$-Ray diffraction patterns of the chosen samples in each category, and Figure 8 shows their surface morphology. Figure 9 shows the crosssection and the surface of the Ni-P layer with no additive before and after corrosion. The chemical composition of these samples, obtained using the EDS technique, are summarized in Table 4 and the average thickness of the coatings with their variations determined by X-ray fluorescence on the complete surface of the samples, can be found in Table 5. The thickness of the Ni-P layer from the cross-section image is in a good agreement with the values measured by X-Ray fluorescence. Figure 11 and Table 6 represent the surface morphology and the average roughness values of the samples obtained by AFM. All the samples present a similar surface morphology containing globular fungi-form features. However, thinner and smoother coatings were formed in the presence of additives. This observation implies that the additives have a noticeable effect on the thickness and roughness of the coatings, but their surface morphology is controlled by other parameters, i.e. coating conditions. With the exception of the sample Sac. 2.5 that has only around $2 \%$ of $\mathrm{P}$, the $\mathrm{P}$ content is around $14 \%$ in the others. The X-ray patterns of all samples, except Sac. 2.5, is similar to the substrate, meaning that the Ni-P layers present a completely amorphous structure. In the X-ray pattern of Sac. 2.5, however, there are two broad peaks related to the presence of crystalline $\mathrm{Ni}$; its structure is a mixture of amorphous and crystalline phases. 


\section{4- Discussion}

The Tafel extrapolation method was employed to extract the summarized data in Table 1, such as corrosion potential ( $\mathrm{E}_{\text {corr }}$ ), corrosion current density ( $\mathrm{i}_{\text {corr }}$ ), anodic and cathodic Tafel slopes $\left(\beta_{\mathrm{a}}\right.$ and $\left.\beta_{\mathrm{c}}\right)$. The polarization resistance $\left(\mathrm{R}_{\mathrm{p}}\right)$ was calculated using the Stern-Geary equation [35] :

$R_{P}=\frac{\beta_{a} \beta_{c}}{2.303\left(\beta_{a}+\beta_{c}\right) i_{c o r r}}$

$\mathrm{i}_{\text {corr }}$ can be used as criterion for comparing the corrosion resistance; a lower $\mathrm{i}_{\text {corr }}$ means a higher corrosion resistance. It is well-known that a localized corrosion process occurs on Ni-P films with a porous $\mathrm{Au}$ top-coat based on the high ratio of cathode area $(\mathrm{Au})$ to anode area $(\mathrm{Ni}-\mathrm{P})$ that leads to a high polarization of the Ni-P film $[19,36,37]$. The current density value at high potential, such as $+0.6 \mathrm{~V}$ vs. OCP, can also be used to simulate the corrosion resistance of different Ni-P layers. Thus, i values measured at a potential of $+0.6 \mathrm{~V}$ vs. OCP for all samples are also presented in Table 1.

Based on the analyzed potentiodynamic data, applying the Ni-P layers on $\mathrm{Cu}$ shifted the corrosion potential to more negative values, decreased the corrosion current density and increased the polarization resistance - meaning that they can act as a sacrificial anode for the $\mathrm{Cu}$ substrate, and thus, eliminate its localized corrosion [31] and improve the corrosion resistance. Moreover, they have higher anodic slopes meaning that the rate of the anodic reaction by the dissolution of metal (Ni for coatings against $\mathrm{Cu}$ for the substrate) has decreased. However, the cathodic slope almost did not change, except some samples in Sac. and Gly. Categories, meaning that the same cathodic reaction rate due to the hydrogen evaluation is observed during the corrosion process. It can be seen that all the presented Tafel plots have almost similar cathodic branches, and while the substrate undergoes a fast active dissolution, the coatings show a pseudo-passivation behavior in their anodic branch; this layer is broken only for Sac. 2.5 and the Ni-P layer with no additives (around $0.1 \mathrm{~V}$ vs. $\mathrm{Ag} / \mathrm{AgCl}$ ), and therefore, they have an accelerated corrosion at high potentials (Figure 3). This feature explains the appearance of these samples after corrosion (Figure 2), where Ni-P and Sac.2.5 are blackened at the edges or completely dissolved, respectively; the other samples kept their primitive shiny gray appearance after the corrosion process. 
Electrochemical impedance spectroscopy (EIS) is a powerful technique to detect the ongoing interfacial reactions and characterize the coating corrosion properties. A simple model consisting of a solution resistance $\left(R_{s}\right)$ in series with a parallel circuit of a constant phase element $\left(\mathrm{CPE}_{\mathrm{dl}}\right)$ and a polarization/charge transfer resistance $\left(\mathrm{R}_{\mathrm{ct}}\right)$ and with a Warburg element (Figure 5.a) has been usually employed to fit the EIS data of copper corrosion in chloride containing solutions. The Warburg element represents the fact that the corrosion of copper is controlled by the diffusion of oxygen through the interface at low frequencies [7] due to the formation of a nonprotective $\mathrm{CuCl}$ film [1]. The fit values for this element were $6059 \Omega . \mathrm{cm}^{2}(\mathrm{~W}-\mathrm{R})$, $165.9 \mathrm{~s}$ (W-T), and 0.43 (W-P). There is no Warburg element for Ni-P coatings though and the Randles model (Figure 5.b) is usually reported to be the best fit for the EIS data [14]. This model is the same as the proposed model for the substrate without the Warburg element.

The CPE is used, because the formed double layer does not usually present an ideal capacitance behavior; its impedance is expressed as:

$Z_{C P E}=\frac{1}{Y_{0}(J \omega)^{n}}$

Where $Y_{0}$ is the admittance constant, $j$ is the imaginary number, $\omega$ is the angular frequency $(\omega=2 \pi f)$ and $n$ is the exponent of CPE. The $n$ value, which varies from 0 to 1 , depends on the surface roughness and heterogeneity because of the non-uniform current distribution [35]. The $n$ value can determine the nature of the electrochemical element; the element is an ideal capacitance if $\mathrm{n}=1$ and it is a Warburg element if $\mathrm{n}$ $=0.5[7]$.

Similar EIS curves, i.e. Nyquist and Bode plots, show that all coatings undergo the same fundamental electrochemical reaction. The presence of a single semi-circle in the Nyquist plots (and a single peak in the Bode-phase plot) of the coatings indicates that the corrosion process involves a single time constant, which corresponds to the charge transfer reaction, meaning that the dissolution of $\mathrm{Ni}$ during the corrosion is the main process. The different radius of the semi-circles is a representative of the different active area where this reaction occurs. The resistance value at low frequencies in the Bode- $\mathrm{Z}$ plot and the extracted data using the proposed impedance models (Table 2) can be used to evaluate the corrosion results. They imply that improving the corrosion resistance of the substrate by applying Ni-P electrodeposited coatings is mainly related to the reduced charge transfer at the interface of electrolyte and electrode. It is believed that the dissolution of Ni occurs 
in the early stages of corrosion that leaves a P-rich film behind. This film then hinders further dissolution of $\mathrm{Ni}$ and decreases the corrosion rate [31].

Using the obtained corrosion resistance from polarization and EIS tests, one can calculate corrosion efficiency (CorE) and porosity density (P.D) of the electrodeposited coatings (Table 3) employing the equations 3 [14] and 4 [38], respectively.

$(\operatorname{CorE} \%)=\left(1-\left(\frac{R_{P S}}{R_{P}}\right)\right) * 100$

P.D $=\frac{R_{p s}}{R_{p}} \times 10^{-\left(\frac{\Delta E}{\beta a}\right)}$

$\Delta E$ is the difference between the corrosion potential of the coated sample and the substrate, $\beta_{a}$ is the anodic slope of the substrate, and $R_{p s}$ and $R_{p}$ are the polarization resistance of the substrate and the coating extracted from Tafel plots, respectively. Charge transfer resistance values obtained from EIS tests, according to reference [39], can be considered equal to polarization resistances, and hence they were inserted in equation (3) to measure the corrosion efficiency. An equation similar to (3) could be employed to calculate the corrosion efficiency at high potentials using the current density values at these potentials (Table 1) bearing in mind that the current density and the polarization resistance have an inverse relationship. The Ni$\mathrm{P}$ layer without additives has a 63.4/55.5 corrosion efficiency \% (using Tafel/EIS test data), a really low corrosion efficiency at high potentials $(-210 \%)$ and $12.8 \%$ of porosity, possibly more around the edges given that the edges blacken after the corrosion tests (Figure 2). The blackened parts proved to be Nickel oxide (NiO) based on EDS analysis. The surface and cross-section morphology of the blackened part is presented in Figure 9. It can be seen that more than half of the Ni-P film is corroded and converted to $\mathrm{NiO}$, leaving a cracked surface behind. The fast $\mathrm{Ni}$ dissolution that blackened the edge left a high P content film (20 wt. \%) with a high internal stress [17], which explains the cracked surface. It should be noticed that the cross-section and surface of the shiny part is intact after corrosion while the $\mathrm{P}$ content has increased. Therefore, one can assume the same for other samples using additives that kept their shiny look after corrosion. It is well known that there is a non-uniform distribution of current around the edges during the deposition that can lead to the formation of a non-uniform coating. There is a pseudo-passivation region in its anodic branch (Figure 3 ) that ends around $-0.1 \mathrm{~V}$ (vs. $\mathrm{Ag} / \mathrm{AgCl}$ ). This could be due 
to the localized attack of chlorine ions at the edges of the Ni-P coatings that led to a galvanic corrosion between copper and nickel, and thus, a fast oxidation of $\mathrm{Ni}$ that blackens the edges; which also explains the high current, and a negative corrosion efficiency at high potentials. The whole surface of the substrate got slightly tarnished and there is a passivation looking-region in its polarization curve at high potentials, possibly due to the oxidation of the surface or the formation of a chlorine film. Based on Figure 2, introducing the additives has homogenized the current distribution; it can be also concluded that employing a proper content of additives can efficiently improve the corrosion efficiency, especially at high potentials, and highly decrease the porosity content (Table 3). This is especially important for the microelectronic contacts, where a severe corrosion phenomenon is reported at their edges, and the presence of a gold top-coat requires a barrier film with a good corrosion resistance at high potentials due to the galvanic corrosion between gold and the Ni-P sublayer $[36,37]$.

\section{4-1- Effect of saccharine as an additive}

The adsorption of additives on the surface of the cathode is reported to affect the activation energy, charge transfer rate in the electrochemical reactions, and electrocrystallization mechanism. Therefore, introducing additives to an electrodeposition bath affects the deposition procedure, and thus, the properties and structure of the obtained coatings [27]. Saccharine is one of the most used brightening agents in the electrodeposition of nickel. Its effect on the brightness of the coatings comes from its ability to refine the grains and increase the cathode polarization. Amorphous films with lower P content can be obtained in the presence of saccharine, because saccharine adsorbs on the cathode surface, limits the number of deposition sites and obstructs the surface diffusion of Ni. As a result, multi-phase deposits can be formed when saccharine is present in the electrolyte. Moreover, the addition of saccharine can also improve the physical properties of the coating because it can inhibit the discharge of protons on the cathode surface [23], and thus, it suppresses the hydrogen evolution reaction during the deposition process [26]. It is also reported that saccharine decreases the internal stress of Ni-P coatings, however, the segregation of sulphur into the grain boundaries can increase the internal stress again in high concentrations [17]. Our results show that even though the instantaneous corrosion resistance has been improved (especially Sac. 2.5), the general corrosion behavior could not be considered appropriate due to the following reasons. The cathodic slopes are lower in the presence of saccharine meaning a higher cathodic reaction rate. The oxidation current densities at the end of experiments are relatively high 
(and thus the corrosion efficiency is low at high potentials). The surface of the coatings have uniformly blackened after the corrosion process, and have completely dissolved at saccharine concentrations above $1 \mathrm{~g} / \mathrm{L}$ (Figure 2). In the case of Sac. 2.5 , the coating has a low $\mathrm{P}$ content $(1.8 \mathrm{wt}$. \%), and a mixed crystalline-amorphous structure. The crystallinity of coatings should be enhanced with increasing saccharin concentration, since it hinders the incorporation of $\mathrm{P}$. Moreover, the common defects of a polycrystalline layer, like grain boundaries, can act as high-speed pathways for the diffusion of copper to the surface during the corrosion process, especially at high potentials [36]. Therefore, a galvanic corrosion phenomenon between nickel in the crystalline state (anode) and the amorphous state (cathode) could be the reason of the blackening/dissolving of the layer in the presence of low/high concentrations of saccharine. This could be also supported by the fact that saccharine shifted the corrosion potentials compared to the Ni-P one. Moreover, Murugan et al. [37] have reported that eliminating the $\mathrm{Ni}$ (crystalline)/Ni-P(amorphous) interface has improved the corrosion performance of stacked layers. This could be easily extended to our results as well. Therefore, employing saccharine as an additive, especially for microelectronics where there is a porous gold topcoat, can lead to the fast corrosion of the barrier layer, and hence, its usage should be avoided for Ni-P thin films.

\section{4-2- Effect of glycine as an additive}

Glycine is another brightener that can be introduced to the electrolyte. It can act as a buffering and complexing agent, and thus, improve the corrosion behavior, increase the brightness, and modify the structure [26,27,34]. Regarding our results, glycine as an additive efficiently improved the corrosion resistance of Ni-P thin films; however, a further increase of its concentration had a negative effect, i.e. the corrosion efficiency decreased by $10 \%-15 \%$ by increasing its concentration from 0.1 to $5 \mathrm{~g} / \mathrm{L}$ based on the Tafel (EIS) data. In comparison to the film with no additives, the coatings possessed a higher anodic slope $\left(\beta_{\mathrm{a}}\right)$ representing a slower anodic

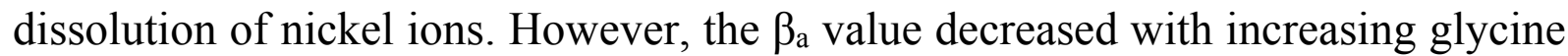
concentration, meaning a faster dissolution of $\mathrm{Ni}$ in the presence of more glycine. This result is in agreement with the data of Guo et al. [40], who used cyclic voltammetry to study the deposition of Ni-Mn films with glycine as complexing agent and showed that the dissolution of $\mathrm{Ni}$ occurs faster in the presence of glycine. The Ni-P coatings present lower cathodic slopes meaning a higher hydrogen evolution rate. The obtained polarization and charge transfer resistances from the corrosion tests show that glycine in low concentrations, i.e. $0.1 \mathrm{~g} / \mathrm{L}$, can improve the 
corrosion efficiency of Ni-P thin films. As it can be seen in Figure 2, the coated samples have kept their appearance after corrosion tests up to a glycine concentration of $2.5 \mathrm{~g} / \mathrm{L}$. At higher concentrations, the surface blackened and the film dissolved mostly at the edges. The EDS analysis showed that glycine, similar to saccharine, can reduce the P content: it decreased from $14.6 \%$ at $0.1 \mathrm{~g} / \mathrm{L}$ glycine to only $6.4 \%$ at $2.5 \mathrm{~g} / \mathrm{L}$ of glycine. Therefore, the same galvanic corrosion phenomenon, however in less extent compared to the saccharine samples, occurred and the surface of the samples blackened in high concentrations. By taking the corrosion efficiency at high potentials into account, it can be concluded that the coatings undergo a fast dissolution at high potentials in concentrations above $1 \mathrm{~g} / \mathrm{L}$ of glycine.

\section{4-3- Effect of pyridinium propyl sulfonate as an additive}

Pyridinium propyl sulfonate (PPS) is an active sulphur containing organic compound that is reported to have a powerful effect on the brightening of $\mathrm{Ni}$ deposits. It was classified as an auxiliary brightener, and it is effective when it is used in a low concentration (0.1- $4 \mathrm{~g} / \mathrm{L})$ [25]. Its usage for Ni-P coatings, however, is not reported so far. Based on the extracted data from corrosion tests, the use of PPS as an additive in low concentrations, i.e. $0.1 \mathrm{~g} / \mathrm{L}$, leads to an improvement of the corrosion performance of Ni-P thin films. However, its effect was diminished by increasing the concentration; the corrosion efficiency decreased about $15 \%$ by the increase of PPS concentration from 0.1 to $4 \mathrm{~g} / \mathrm{L}$. This is especially evident for the corrosion efficiency at high potentials, where almost a $100 \%$ drop can be seen as the concentration increased. Moreover, exfoliation of the coatings during the corrosion process occurred in concentrations above $1 \mathrm{~g} / \mathrm{L}$ (Figure 2). Pyridinium presents a cationic nature when it is added to acidic solutions [41,42]. Therefore, it competes with metal ions during the deposition procedure and can suppress the cation reactions. As a result, the use of high concentrations of PPS can degrade the coating quality, including an easy exfoliation by weakening the bond strength between the substrate and the coating [43].

\section{4-4- Effect of coumarin as an additive}

Coumarin is reported to lead to coatings with a shiny look, good conductivity, and proper mechanical properties. However, it is known to highly increase the internal stress and brittleness, and hence, its concentration should be kept as low as possible $(0.005-0.2 \mathrm{~g} / \mathrm{L})[25,29,44]$. Moreover, its toxic nature is another reason to use it only in low concentrations [45]. Table 1 to Table 3 show that coumarin even used in very small quantities has improved the corrosion behavior. The corrosion efficiency 
of Ni-P thin films increased by about 25\% (about 300\% at high potentials) by adding $5 \mathrm{mg} / \mathrm{L}$ of coumarin; the Ni-P films kept their appearance after the corrosion tests (Figure 2). Meanwhile, the addition of $5 \mathrm{mg} / \mathrm{L}$ of coumarin increased the $\mathrm{P}$ content by $3.4 \%$ and such high $\mathrm{P}$ content gave Cou. $5 \mathrm{~m}$ an amorphous structure. However, no meaningful relation between the additive concentration and the corrosion resistance can be observed, possibly due to the small range of tested concentrations compared to the other additives.

\section{4-5- Effect of sodium citrate as an additive}

Sodium citrate can act as brightening, leveling, and buffering agent in electrodeposition electrolytes, and thus, eliminates the need for other additives [11]. However, it is mainly known as a complexing agent, and thus, the deposition occurs from $\mathrm{Ni}$ ions in complex form, not free ions. Higher bath stability, higher deposition rate, lower roughness, and better corrosion resistance are the reported effects of using sodium citrate as an additive for coatings [16,30,46]. Our results show that sodium citrate, which is relatively inexpensive, has interestingly improved the corrosion behavior of Ni-P films and their appearance was intact after the corrosion process. Moreover, 4.8\% more $\mathrm{P}$ content was incorporated inside the Ni-P layer in its presence $(4 \mathrm{~g} / \mathrm{L})$ that explains its amorphous structure. However, increasing the concentration from 4 to $20 \mathrm{~g} / \mathrm{L}$ slightly decreased the corrosion efficiency.

\section{4-6- Effect of cerium sulfate as an additive}

Finally, it has been reported that a slight addition of rare earth metals, such as $\mathrm{Ce}$, $\mathrm{Yb}$, and $\mathrm{La}$, into deposition electrolytes refines the microstructure, decreases the grain size and improves the corrosion resistance of the obtained coatings. Rare metals tend to adsorb and form a thin film on the surface of the substrate preferentially on crystal defects such as dislocations and grain boundaries - due to their unique $4 \mathrm{f}$ electron configuration, strong adsorption capacity, low electronegativity, and large atomic radius. Therefore, they decrease the amount of catalytic sites, hinder the electron transfer among ions, reduce the surface energy and increase the nucleation rate, which refines the deposited coatings. Moreover, it was demonstrated that rare metals are not incorporated inside the deposited film, and thus, they are not consumed during the process [31]. Our results show a better corrosion efficiency, both instantaneous and at high potential, and better appearance after the corrosion tests in the presence of cerium sulfate compared to its absence. The corrosion resistance notably increased by increasing its concentration to $8 \mathrm{mg} / \mathrm{L}$; a further increase of concentration decreased the efficiency. This result is in 
accordance with Huang et al. [31], who suggested that a small amount of Ce ion addition decreases the defect density of coatings; however, they will also hinder the deposition of ions and lower the deposition rate. Therefore, they diminish the coating quality and corrosion resistance in high concentrations. As conclusion, the effect of the addition of rare earth metals on the properties of the deposited coatings completely depends on their concentration.

4-7- Comparison of the effects of each additive added in the selected concentration on the properties of thin Ni-P coatings

As a conclusion of the experiments described above, Sac. 2.5, Gly. 0.1, Pyr. 0.1, Cou. $5 \mathrm{~m}$, Cit. 4 , and Ce. $8 \mathrm{~m}$ were chosen as the best samples in each category with regard to the corrosion resistance. Figure 6 presents the corrosion efficiency of these samples; instantaneous and at high potentials.

By measuring the coating mass and its chemical composition, one can employ the following equation to calculate the coating efficiency [47]:

$$
C E \%=\frac{m F}{I t} \sum \frac{c_{i}}{n_{i}}
$$

Where $\mathrm{m}$ is the coating mass ( $\mathrm{g}$ ), $\mathrm{F}$ is Faraday's constant $(96485 \mathrm{C} / \mathrm{mol})$, I is the total current $(\mathrm{A}), \mathrm{t}$ is the deposition time $(\mathrm{s}), \mathrm{c}_{i}$ is the mass fraction of the element $(\mathrm{Ni}$, and $\mathrm{P})$, and $\mathrm{n}_{\mathrm{i}}$ is the number of transferred electrons.

The measured mass, thickness, and coating efficiency of the chosen samples in each category are presented in Table 5 . It is obvious that introducing the additives to the electrolyte decreased the coating efficiency from $3.5 \%$ (Sac. 2.5) to $5 \%$ (Cou. $5 \mathrm{~m}$ ). Therefore, it can be concluded that employing the additives leads to coatings with higher corrosion efficiency and lower coating efficiency, respectively. Moreover, all the coatings are amorphous, except Sac. 2.5 that has a mixed crystalline-amorphous structure. Figure 9 shows the cross-section of the Ni-P layer with no additive: it can be seen that a uniform compact coating has been formed. As it was suspected, the addition of these compounds have decreased the average coating thickness, i.e. from about $1 \mu \mathrm{m}$ for Sac. 2.5 to $1.7 \mu \mathrm{m}$ for Gly.0.1 compared to the thickness of the Ni-P layer with no additives (Table 5). However, the thickness variation has also decreased, meaning that a more uniform coating was formed in the presence of additives (1.01 $\mu \mathrm{m}$ for Ni-P vs. $0.16 \mu \mathrm{m}$ for Gly.0.1). Furthermore, again except Sac. 2.5 , they have higher $\mathrm{P}$ content, lower roughness, and better stability at high potentials compared to the Ni-P layer with no additives. However, all the additives, including saccharine, decreased the porosity content, leading as the same time to an 
improvement of the instantaneous corrosion resistance. Table 6 shows that employing additives, except saccharine, can decrease the surface roughness from 31 $\mathrm{nm}$ (Cou. $5 \mathrm{~m})$ to $186 \mathrm{~nm}$ (Pyr.0.1) with respect to their absence $(341 \mathrm{~nm})$. It is well known that coatings with higher quality and better properties form on smoother substrates, and the roughness of the substrate has an important impact on the physical properties of multilayer coatings [48,49]. Therefore, the ability of these additives to smooth the surface is especially important for electrical contacts where there is a gold top-coat. The porosity content of this top-coat is known to be the most important parameter determining the lifetime of microelectronic devices. It was reported that decreasing the substrate roughness from $0.4 \mu \mathrm{m}$ to $0.2 \mu \mathrm{m}$ decreased the electrographic porosity index of the gold layer by about ten times [50].

In order to investigate the relationship between the $\mathrm{P}$ content, the corrosion efficiency and coating efficiency of the amorphous Ni-P layers, the P content of the samples with glycine and cerium sulfate as additives was measured using the EDS technique. Figure 10 depicts the $\mathrm{P}$ content, corrosion efficiency and coating efficiency of coatings with glycine and cerium sulfate as function of their concentration. While there is a similar trend for the corrosion efficiency and $\mathrm{P}$ content, there is no trend for the coating efficiency as function of the concentration of additives. Therefore, the $\mathrm{P}$ content definitely plays an important role in determining the corrosion behavior of amorphous Ni-P layers.

\section{5- Conclusions}

In this paper, we have investigated the effects of different additives on the properties of Ni-P thin films. Based on our results, it can be concluded:

- The P content plays an important role for the corrosion resistance of amorphous Ni-P films: a higher P content improves the corrosion resistance.

- In the presence of additives, thinner and more uniform coatings with similar surface morphology are formed. However, they decreased the coating efficiency.

- Employing the proper concentration of additives effectively enhanced the corrosion efficiency of Ni-P thin films.

- Saccharine improved the instantaneous corrosion resistance; however, an accelerated corrosion at high potentials was observed so that its usage should be avoided in electronics. Moreover, Saccharine decreased the incorporation 
of $\mathrm{P}$ inside the Ni lattice and thus a mixed crystalline amorphous structure was formed when saccharine was in the electrolyte.

- Glycine and PPS, especially in low concentrations, proved to be effective additives to improve the corrosion efficiency of Ni-P layers, decreased the roughness and increased the uniformity of the coatings. A further increase of their concentration, however, had a negative effect on corrosion properties of Ni-P layers.

- Coumarin and cerium sulfate can be considered as interesting additives, because even a low concentration of them $(\mathrm{mg} / \mathrm{L})$ noticeably enhanced the properties of amorphous Ni-P thin films.

- Sodium citrate proved to be an effective (and economical) additive to improve the properties of Ni-P coatings; its impact depended only slightly on its concentration.

\section{Acknowledgment}

This work was supported by the French government through the program "Investissements d'Avenir A*MIDEX" (Project APODISE, No. ANR-11-IDEX0001-02) managed by the National Agency for Research (ANR).

\section{References}

[1] E.-S.M. Sherif, Effects of 2-amino-5-(ethylthio)-1,3,4-thiadiazole on copper corrosion as a corrosion inhibitor in 3\% NaCl solutions, Appl. Surf. Sci. 252 (2006) 8615-8623. doi:10.1016/j.apsusc.2005.11.082.

[2] S. Adhami, M. Atapour, A.R. Allafchian, Corrosion protection of copper by silane sol-gel coatings, J. Sol-Gel Sci. Technol. 74 (2015) 800-809. doi:10.1007/s10971-015-3665-9.

[3] E.M. Sherif, S.-M. Park, Inhibition of Copper Corrosion in 3.0\% NaCl Solution by N-Phenyl-1,4phenylenediamine, J. Electrochem. Soc. 152 (2005) B428. doi:10.1149/1.2018254.

[4] S. Kologo, M. Eyraud, L. Bonou, F. Vacandio, Y. Massiani, Voltametry and EQCM study of copper oxidation in acidic solution in presence of chloride ions, Electrochimica Acta. 52 (2007) 3105-3113. doi:10.1016/j.electacta.2006.09.052.

[5] Y.E. Sknar, O.O. Savchuk, I.V. Sknar, Characteristics of electrodeposition of Ni and Ni-P alloys from methanesulfonate electrolytes, Appl. Surf. Sci. 423 (2017) 340-348. doi:10.1016/j.apsusc.2017.06.146.

[6] J. Zhang, Z. Liu, G.-C. Han, S.-L. Chen, Z. Chen, Inhibition of copper corrosion by the formation of Schiff base self-assembled monolayers, Appl. Surf. Sci. 389 (2016) 601-608. doi:10.1016/j.apsusc.2016.07.116.

[7] Y. Yu, D. Yang, D. Zhang, Y. Wang, L. Gao, Anti-corrosion film formed on HAl77-2 copper alloy surface by aliphatic polyamine in 3wt.\% NaCl solution, Appl. Surf. Sci. 392 (2017) 768-776. doi:10.1016/j.apsusc.2016.09.118. 
[8] Z. Zhang, Q. Wang, X. Wang, L. Gao, The influence of crystal faces on corrosion behavior of copper surface: First-principle and experiment study, Appl. Surf. Sci. 396 (2017) 746-753. doi:10.1016/j.apsusc.2016.11.020.

[9] B.D. Falola, I.I. Suni, Low temperature electrochemical deposition of highly active elements, Curr. Opin. Solid State Mater. Sci. 19 (2015) 77-84. doi:10.1016/j.cossms.2014.11.006.

[10] N. Ait Ahmed, M. Eyraud, H. Hammache, F. Vacandio, S. Sam, N. Gabouze, P. Knauth, K. Pelzer, T. Djenizian, New insight into the mechanism of cathodic electrodeposition of zinc oxide thin films onto vitreous carbon, Electrochimica Acta. 94 (2013) 238-244. doi:10.1016/j.electacta.2013.01.103.

[11] R. Oriňáková, A. Turoňová, D. Kladeková, M. Gálová, R.M. Smith, Recent developments in the electrodeposition of nickel and some nickel-based alloys, J. Appl. Electrochem. 36 (2006) 957-972. doi:10.1007/s10800-006-9162-7.

[12] E. Pellicer, S. Pané, K.M. Sivaraman, O. Ergeneman, S. Suriñach, M.D. Baró, B.J. Nelson, J. Sort, Effects of the anion in glycine-containing electrolytes on the mechanical properties of electrodeposited Co-Ni films, Mater. Chem. Phys. 130 (2011) 1380-1386. doi:10.1016/j.matchemphys.2011.09.032.

[13] W. Li, S. Zhang, In situ ellipsometric study of electrodeposition of manganese films on copper, Appl. Surf. Sci. 257 (2011) 3275-3280. doi:10.1016/j.apsusc.2010.10.155.

[14] A.R. Madram, H. Pourfarzad, H.R. Zare, Study of the corrosion behavior of electrodeposited Ni-P and Ni-P-C nanocomposite coatings in $1 \mathrm{M} \mathrm{NaOH}$, Electrochimica Acta. 85 (2012) 263-267. doi:10.1016/j.electacta.2012.08.061.

[15] A.M. Pillai, A. Rajendra, A.K. Sharma, Electrodeposited nickel-phosphorous (Ni-P) alloy coating: an in-depth study of its preparation, properties, and structural transitions, J. Coat. Technol. Res. 9 (2012) 785-797. doi:10.1007/s11998-012-9411-0.

[16] M.S. Nur Ariffah, M.S. Nurulakmal, A.S. Anasyida, E.K. Shiu, Effect of Complexing Agent in Ni-P Coating on Cu Substrate, Mater. Sci. Forum. 819 (2015) 97-102. doi:10.4028/www.scientific.net/MSF.819.97.

[17] L. Chang, C.-H. Chen, H. Fang, Electrodeposition of Ni-P Alloys From a Sulfamate Electrolyte, J. Electrochem. Soc. 155 (2008) D57. doi:10.1149/1.2803516.

[18] F. Vacandio, Y. Massiani, M. Eyraud, S. Rossi, L. Fedrizzi, Influence of various nickel under-layers on the corrosion behaviour of AIN films deposited by reactive sputtering, Surf. Coat. Technol. 137 (2001) 284-292. doi:10.1016/S0257-8972(00)01110-5.

[19] Z.H. Huang, Y.J. Zhou, W. He, A combination of self-assembled monolayer and hydrophobic conformal coating for anti-corrosion of $\mathrm{Cu} / \mathrm{NiP} / \mathrm{Au} 3 \mathrm{D}$ circuitry in artificial sweat solution, Surf. Coat. Technol. 320 (2017) 126-131. doi:10.1016/j.surfcoat.2017.01.087.

[20] M. Uysal, H. Akbulut, M. Tokur, H. Algül, T. Çetinkaya, Structural and sliding wear properties of $\mathrm{Ag} / \mathrm{Graphene/WC}$ hybrid nanocomposites produced by electroless co-deposition, J. Alloys Compd. 654 (2016) 185-195. doi:10.1016/j.jallcom.2015.08.264.

[21] J. Lamovec, V. Jović, I. Mladenović, M. Sarajlić, V. Radojević, Assessment of the composite behavior of different Ni/Cu multilayer composite systems, in: 2014 29th Int. Conf. Microelectron. Proc. MIEL 2014, 2014: pp. 183-186. doi:10.1109/MIEL.2014.6842116.

[22] X. Leng, Smart card applications and security, Inf. Secur. Tech. Rep. 14 (2009) 36-45. doi:10.1016/j.istr.2009.06.006.

[23] Z.H. Fang, Electrodeposition of amorphous Ni-P alloy coatings, CAS OpenIR. (1997). http://ir.ipe.ac.cn/handle/122111/5910 (accessed September 13, 2017).

[24] L. Bonou, M. Eyraud, R. Denoyel, Y. Massiani, Influence of additives on Cu electrodeposition mechanisms in acid solution: direct current study supported by non-electrochemical measurements, Electrochimica Acta. 47 (2002) 4139-4148. doi:10.1016/S0013-4686(02)00356-0. 
[25] G.A. Di Bari, Electrodeposition of Nickel, in: Mod. Electroplat., John Wiley \& Sons, Inc., 2010: pp. 79-114. doi:10.1002/9780470602638.ch3.

[26] C.D. Grill, I. Pötzelberger, J.P. Kollender, A.W. Hassel, Cobalt-nickel material libraries obtained from electrodeposition using citrate or glycine as additives: Co-Ni material libraries from citrate or glycine containing bath, Phys. Status Solidi A. 213 (2016) 1417-1426. doi:10.1002/pssa.201532779.

[27] I.H. Karahan, Effects of pH Value of the Electrolyte and Glycine Additive on Formation and Properties of Electrodeposited Zn-Fe Coatings, Sci. World J. 2013 (2013) 1-7. doi:10.1155/2013/273953.

[28] Y. Li, H. Jiang, D. Wang, H. Ge, Effects of saccharin and cobalt concentration in electrolytic solution on microhardness of nanocrystalline Ni-Co alloys, Surf. Coat. Technol. 202 (2008) 4952-4956. doi:10.1016/j.surfcoat.2008.04.093.

[29] S.T. Aruna, P.G. Lashmi, H.M. Seema, The effect of additives on the properties of electrodeposited Ni-zircon composite coatings, RSC Adv. 6 (2016) 11185-11192. doi:10.1039/C5RA25119B.

[30] X.-C. Wang, W.-B. Cai, W.-J. Wang, H.-T. Liu, Z.-Z. Yu, Effects of ligands on electroless Ni-P alloy plating from alkaline citrate-ammonia solution, Surf. Coat. Technol. 168 (2003) 300-306. doi:10.1016/S0257-8972(03)00013-6.

[31] G. Liu, Z. Huang, L. Wang, W. Sun, S. Wang, X. Deng, Effects of Ce4+ on the structure and corrosion resistance of electroless deposited Ni-Cu-P coating, Surf. Coat. Technol. 222 (2013) 25-30. doi:10.1016/j.surfcoat.2013.01.053.

[32] Y.D. Gamburg, G. Zangari, Electrodeposition of Alloys, in: Theory Pract. Met. Electrodepos., Springer New York, New York, NY, 2011: pp. 205-232. http://link.springer.com/10.1007/978-14419-9669-5_10 (accessed May 16, 2017).

[33] L. Elias, A.C. Hegde, Synthesis and characterization of Ni-P-Ag composite coating as efficient electrocatalyst for alkaline hydrogen evolution reaction, Electrochimica Acta. 219 (2016) 377-385. doi:10.1016/j.electacta.2016.10.024.

[34] R. Tarozaitė, Z. Sukackienè, A. Sudavičius, R. Juškėnas, A. Selskis, A. Jagminienè, E. Norkus, Application of glycine containing solutions for electroless deposition of Co-P and Co-W-P films and their behavior as barrier layers, Mater. Chem. Phys. 117 (2009) 117-124. doi:10.1016/j.matchemphys.2009.05.016.

[35] A. Bahramian, K. Raeissi, A. Hakimizad, An investigation of the characteristics of Al2O3/TiO2 PEO nanocomposite coating, Appl. Surf. Sci. 351 (2015) 13-26. doi:10.1016/j.apsusc.2015.05.107.

[36] V.K. Murugan, Z. Jia, G.J. Syaranamual, C.L. Gan, Y. Huang, Z. Chen, Atmospheric corrosion resistance of electroplated Ni/Ni-P/Au electronic contacts, Microelectron. Reliab. 60 (2016) 84-92. doi:10.1016/j.microrel.2016.02.014.

[37] V.K. Murugan, Z. Jia, G.J. Syaranamual, C.L. Gan, Y. Huang, Z. Chen, An investigation into different nickel and nickel-phosphorus stacked thin coatings for the corrosion protection of electrical contacts, Surf. Coat. Technol. 300 (2016) 95-103. doi:10.1016/j.surfcoat.2016.05.013.

[38] H. Mazaheri, S.R. Allahkaram, Deposition, characterization and electrochemical evaluation of $\mathrm{Ni}-$ P-nano diamond composite coatings, Appl. Surf. Sci. 258 (2012) 4574-4580. doi:10.1016/j.apsusc.2012.01.031.

[39] J.R. Macdonald, W.R. Kenan, Impedance Spectroscopy: Emphasizing Solid Materials and Systems, Wiley, 1987.

[40] J. Guo, X. Guo, S. Wang, Z. Zhang, J. Dong, L. Peng, W. Ding, Effects of glycine and current density on the mechanism of electrodeposition, composition and properties of $\mathrm{Ni}-\mathrm{Mn}$ films prepared in ionic liquid, Appl. Surf. Sci. 365 (2016) 31-37. doi:10.1016/j.apsusc.2015.12.248.

[41] H. Xing, T. Wang, Z. Zhou, Y. Dai, The sulfonic acid-functionalized ionic liquids with pyridinium cations: Acidities and their acidity-catalytic activity relationships, J. Mol. Catal. Chem. 264 (2007) 53-59. doi:10.1016/j.molcata.2006.08.080. 
[42] X. Wang, J. Hao, Recent advances in ionic liquid-based electrochemical biosensors, Sci. Bull. 61 (2016) 1281-1295. doi:10.1007/s11434-016-1151-6.

[43] S.W. Jiang, L. Yang, J.N. Pang, H. Lin, Z.Q. Wang, Electrodeposition of Ni-Al2O3 composite coatings with combined addition of SDS and HPB surfactants, Surf. Coat. Technol. 286 (2016) 197-205. doi:10.1016/j.surfcoat.2015.12.028.

[44] Y. Li, H. Jiang, D. Wang, H. Ge, Effects of saccharin and cobalt concentration in electrolytic solution on microhardness of nanocrystalline Ni-Co alloys, Surf. Coat. Technol. 202 (2008) 4952-4956. doi:10.1016/j.surfcoat.2008.04.093.

[45] Y. Tanaka, W. Fujii, H. Hori, Y. Kitagawa, K. Ozaki, Relationship between coumarin-induced hepatocellular toxicity and mitochondrial function in rats, Food Chem. Toxicol. 90 (2016) 1-9. doi:10.1016/j.fct.2016.01.007.

[46] G.-F. Huang, W.-Q. Huang, L.-L. Wang, B.-S. Zou, D.-P. Chen, D.-Y. Li, J.-M. Wei, J.-H. Zhang, Effects of Complexing Agents on the Corrosion Resistance of Electroless Ni-Fe-P Alloys, Int J Electrochem Sci. 2 (2007) 321-328.

[47] X. Qiao, H. Li, W. Zhao, D. Li, Effects of deposition temperature on electrodeposition of zinc-nickel alloy coatings, Electrochimica Acta. 89 (2013) 771-777. doi:10.1016/j.electacta.2012.11.006.

[48] S.-H. Jeon, W.-I. Choi, G.-D. Song, Y.-H. Son, D.H. Hur, Influence of Surface Roughness and Agitation on the Morphology of Magnetite Films Electrodeposited on Carbon Steel Substrates, Coatings. 6 (2016) 62. doi:10.3390/coatings6040062.

[49] S. Lin, K. Zhou, M. Dai, F. Hu, Q. Shi, H. Hou, C. Wei, F. Li, X. Tong, Effects of surface roughness of substrate on properties of Ti/TiN/Zr/ZrN multilayer coatings, Trans. Nonferrous Met. Soc. China. 25 (2015) 451-456. doi:10.1016/S1003-6326(15)63623-8.

[50] M. Braunovic, N.K. Myshkin, V.V. Konchits, Electrical Contacts: Fundamentals, Applications and Technology, CRC Press, 2006. 
Tables

Table 1. Analyzed data from Potentiodynamic polarization tests

\begin{tabular}{|c|c|c|c|c|c|c|c|}
\hline \multirow{2}{*}{\multicolumn{2}{|c|}{ Sample }} & \multirow{2}{*}{$\begin{array}{c}\mathrm{i}_{\text {corr }} \\
\left(\mu \mathrm{A} \cdot \mathrm{cm}^{-2}\right)\end{array}$} & \multirow{2}{*}{$\begin{array}{c}\mathrm{E}_{\text {corr }} \\
(\mathrm{mV}) \\
\text { vs. } \\
\mathrm{Ag} / \mathrm{AgCl}\end{array}$} & \multicolumn{2}{|c|}{$\begin{array}{l}\text { Average Tafel slope } \\
\quad\left(\mathrm{mV} \cdot \mathrm{dec}^{-1}\right)\end{array}$} & \multirow{2}{*}{$\begin{array}{c}\mathrm{R}_{\mathrm{p}} \\
\left(\mathrm{k} \Omega \cdot \mathrm{cm}^{2}\right)\end{array}$} & \multirow{2}{*}{$\begin{array}{c}\mathrm{i}\left(\mathrm{mA} \cdot \mathrm{cm}^{-2}\right) \\
\text { at }+0.6 \mathrm{~V} \text { vs } \\
\text { OCP }\end{array}$} \\
\hline & & & & $\beta_{a}$ & $\beta_{\mathrm{c}}$ & & \\
\hline \multicolumn{2}{|c|}{ Substrate $(\mathrm{Cu})$} & 3.32 & -200 & 66 & 195 & 6.4 & 5.12 \\
\hline \multicolumn{2}{|c|}{ Ni-P } & 1.69 & -302 & 108 & 184 & 17.5 & 15.86 \\
\hline \multirow{5}{*}{ Saccharin } & Sac.0.1 & 1.49 & -274 & 202 & 143 & 24.3 & 7.24 \\
\hline & Sac.0.5 & 1.24 & -288 & 236 & 136 & 28.6 & 3.46 \\
\hline & Sac.1 & 1.32 & -256 & 105 & 125 & 23.6 & 16.92 \\
\hline & Sac. 2.5 & 0.83 & -246 & 266 & 119 & 42.9 & 3.32 \\
\hline & Sac.5 & 1.11 & -241 & 84 & 167 & 24.8 & 13.65 \\
\hline \multirow{5}{*}{ Glycine } & Gly.0.1 & 0.94 & -296 & 230 & 156 & 42.7 & 0.10 \\
\hline & Gly.0.5 & 1.15 & -324 & 191 & 152 & 32.5 & 0.08 \\
\hline & Gly.1 & 1.27 & -302 & 188 & 138 & 27.4 & 18.85 \\
\hline & Gly.2.5 & 1.42 & -284 & 172 & 159 & 25.1 & 19.73 \\
\hline & Gly.5 & 1.51 & -286 & 162 & 166 & 25.1 & 15.12 \\
\hline \multirow{5}{*}{ PPS } & Pyr.0.1 & 0.82 & -298 & 188 & 188 & 50.4 & 0.22 \\
\hline & Pyr.0.5 & 0.84 & -310 & 196 & 186 & 49.0 & 0.72 \\
\hline & Pyr.1 & 1.85 & -263 & 159 & 251 & 26.0 & 1.74 \\
\hline & Pyr.2 & 2.22 & -285 & 215 & 230 & 21.9 & 3.98 \\
\hline & Pyr.4 & 1.72 & -266 & 149 & 256 & 23.6 & 6.05 \\
\hline \multirow{5}{*}{ Coumarin } & Cou. $5 \mathrm{~m}$ & 0.83 & -310 & 187 & 169 & 46.9 & 0.68 \\
\hline & Cou. $10 \mathrm{~m}$ & 1.51 & -290 & 156 & 222 & 29.6 & 1.74 \\
\hline & Cou. $50 \mathrm{~m}$ & 0.86 & -300 & 161 & 190 & 44.1 & 0.83 \\
\hline & Cou. $100 \mathrm{~m}$ & 0.84 & -290 & 194 & 190 & 49.7 & 1.01 \\
\hline & Cou. $250 \mathrm{~m}$ & 1.00 & -303 & 156 & 176 & 36.3 & 0.35 \\
\hline \multirow{5}{*}{$\begin{array}{l}\text { Sodium } \\
\text { Citrate }\end{array}$} & Cit.4 & 0.74 & -296 & 170 & 180 & 51.6 & 0.09 \\
\hline & Cit. 8 & 0.72 & -309 & 174 & 155 & 49.7 & 0.05 \\
\hline & Cit.12 & 0.80 & -312 & 164 & 163 & 45.2 & 0.08 \\
\hline & Cit.16 & 1.02 & -295 & 168 & 200 & 38.4 & 0.19 \\
\hline & Cit.20 & 0.74 & -308 & 151 & 142 & 43.2 & 0.23 \\
\hline \multirow{5}{*}{$\begin{array}{l}\text { Cerium } \\
\text { Sulfate }\end{array}$} & Ce. $4 \mathrm{~m}$ & 0.96 & -292 & 182 & 192 & 42.6 & 1.29 \\
\hline & Ce. $8 \mathrm{~m}$ & 0.75 & -284 & 200 & 192 & 57.2 & 0.69 \\
\hline & Ce. $12 \mathrm{~m}$ & 0.88 & -300 & 150 & 198 & 41.8 & 1.58 \\
\hline & Ce. $20 \mathrm{~m}$ & 0.82 & -290 & 170 & 172 & 45.3 & 0.67 \\
\hline & Ce. $30 \mathrm{~m}$ & 1.19 & -287 & 202 & 210 & 37.5 & 1.15 \\
\hline
\end{tabular}


Table 2. Analyzed data from EIS tests

\begin{tabular}{|c|c|c|c|c|c|}
\hline \multirow{2}{*}{\multicolumn{2}{|c|}{ Sample }} & \multirow{2}{*}{$\mathrm{R}_{\mathrm{s}}\left(\Omega \cdot \mathrm{cm}^{2}\right)$} & \multicolumn{2}{|c|}{$\mathrm{CPE}_{\mathrm{dl}}$} & \multirow{2}{*}{$\begin{array}{c}\mathrm{R}_{\mathrm{ct}} \\
\left(\mathrm{k} \Omega \cdot \mathrm{cm}^{2}\right)\end{array}$} \\
\hline & & & $\begin{array}{c}\text { CPE-T } \\
\left(\mu \mathrm{F} \cdot \mathrm{cm}^{-2} \cdot \mathrm{s}^{\mathrm{n}-1}\right)\end{array}$ & CPE-P & \\
\hline \multicolumn{2}{|c|}{ Substrate $(\mathrm{Cu})$} & 20.3 & 129.8 & 0.80 & 0.02 \\
\hline \multicolumn{2}{|c|}{$\mathrm{Ni}-\mathrm{P}$} & 12.0 & 42.4 & 0.89 & 13.7 \\
\hline \multirow{5}{*}{ Saccharin } & Sac. 0.1 & 47.7 & 30.2 & 0.94 & 14.4 \\
\hline & Sac. 0.5 & 61.9 & 33.0 & 0.87 & 21.2 \\
\hline & Sac.1 & 16.2 & 26.5 & 0.89 & 20.2 \\
\hline & Sac. 2.5 & 118.8 & 24.8 & 0.90 & 44.8 \\
\hline & Sac. 5 & 15.2 & 16.4 & 0.89 & 25.1 \\
\hline \multirow{5}{*}{ Glycine } & Gly.0.1 & 91.9 & 24.5 & 0.95 & 40.0 \\
\hline & Gly.0.5 & 65.0 & 31.4 & 0.94 & 25.2 \\
\hline & Gly.1 & 14.2 & 23.6 & 0.92 & 23.8 \\
\hline & Gly.2.5 & 14.9 & 25.2 & 0.91 & 21.3 \\
\hline & Gly.5 & 17.3 & 28.0 & 0.91 & 20.2 \\
\hline \multirow{5}{*}{ PPS } & Pyr.0.1 & 16.6 & 28.9 & 0.95 & 40.2 \\
\hline & Pyr.0.5 & 14.5 & 33.6 & 0.93 & 38.5 \\
\hline & Pyr.1 & 18.5 & 46.5 & 0.90 & 23.9 \\
\hline & Pyr.2 & 12.8 & 66.0 & 0.91 & 16.0 \\
\hline & Pyr.4 & 13.6 & 61.5 & 0.90 & 19.3 \\
\hline \multirow{5}{*}{ Coumarin } & Cou. $5 \mathrm{~m}$ & 16.3 & 24.4 & 0.95 & 38.7 \\
\hline & Cou.10m & 19.1 & 23.2 & 0.94 & 27.4 \\
\hline & Cou. $50 \mathrm{~m}$ & 14.0 & 26.8 & 0.94 & 36.6 \\
\hline & Cou. $100 \mathrm{~m}$ & 15.7 & 36.2 & 0.92 & 43.5 \\
\hline & Cou. $250 \mathrm{~m}$ & 17.1 & 36.1 & 0.94 & 27.5 \\
\hline \multirow{5}{*}{$\begin{array}{l}\text { Sodium } \\
\text { Citrate }\end{array}$} & Cit.4 & 64.4 & 27.5 & 0.95 & 40.0 \\
\hline & Cit. 8 & 67.1 & 25.9 & 0.95 & 35.3 \\
\hline & Cit.12 & 56.7 & 26.4 & 0.94 & 29.6 \\
\hline & Cit.16 & 66.5 & 28.1 & 0.94 & 32.1 \\
\hline & Cit.20 & 69.3 & 29.2 & 0.93 & 30.7 \\
\hline \multirow{5}{*}{$\begin{array}{l}\text { Cerium } \\
\text { Sulfate }\end{array}$} & Ce.4m & 12.6 & 27.2 & 0.94 & 38.7 \\
\hline & Ce. $8 \mathrm{~m}$ & 13.1 & 25.5 & 0.95 & 46.6 \\
\hline & Ce. $12 \mathrm{~m}$ & 14.2 & 26.4 & 0.94 & 31.8 \\
\hline & Ce. $20 \mathrm{~m}$ & 13.0 & 28.9 & 0.95 & 36.7 \\
\hline & Ce. $30 \mathrm{~m}$ & 14.0 & 40.8 & 0.92 & 33.4 \\
\hline
\end{tabular}


Table 3. Corrosion efficiency and porosity density of the obtained Ni-P coatings

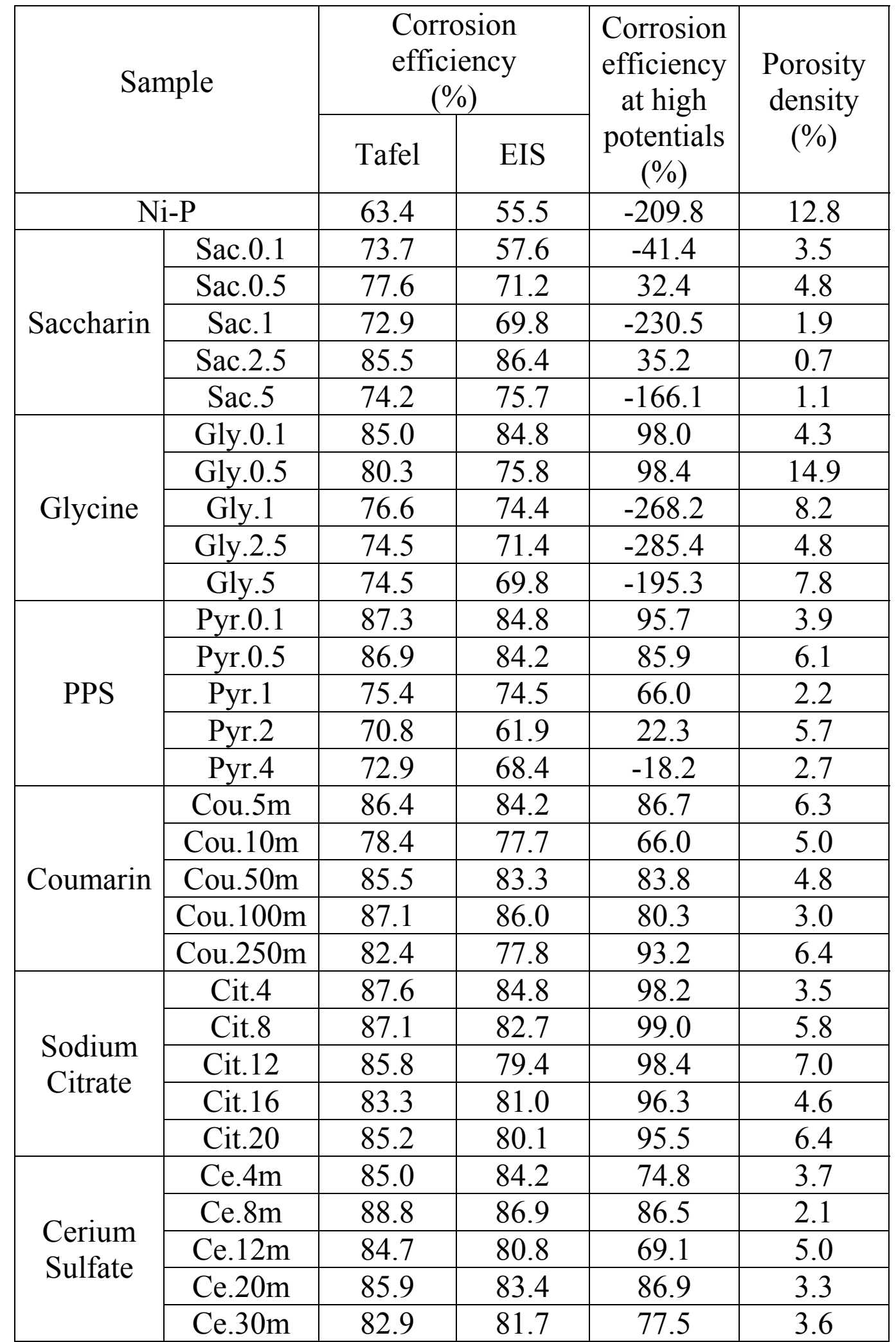


Table 4. Chemical composition of the chosen samples in each category obtained by EDS technique

\begin{tabular}{|c|c|c|}
\hline $\begin{array}{c}\text { Element } \\
\text { Sample }\end{array}$ & Ni (wt. \%) & P (wt. \%) \\
\hline $\begin{array}{c}\text { No } \\
\text { additives }\end{array}$ & 89.5 & 10.5 \\
\hline Sac. 2.5 & 98.2 & 1.8 \\
\hline Gly. 0.1 & 85.4 & 14.6 \\
\hline Pyr. 0.1 & 82.6 & 14.4 \\
\hline Cou. 5m & 82.2 & 13.9 \\
\hline Cit. 4 & 84.7 & 15.3 \\
\hline Ce. $8 \mathrm{~m}$ & 81.2 & 14.6 \\
\hline
\end{tabular}


Table 5. Mass, area, thickness, and coating efficiency of the chosen samples

\begin{tabular}{|c|c|c|c|c|}
\hline Sample & $\begin{array}{c}\mathrm{m} \\
(\mathrm{mg})\end{array}$ & $\begin{array}{c}\mathrm{A} \\
\left(\mathrm{cm}^{2}\right)\end{array}$ & $\begin{array}{c}\mathrm{t} \\
(\mu \mathrm{m})\end{array}$ & $\mathrm{CE} \%$ \\
\hline $\begin{array}{c}\text { No } \\
\text { additives }\end{array}$ & 14.7 & 3.46 & $2.74 \pm 1.01$ & 13.2 \\
\hline Sac. 2.5 & 5.3 & 4.03 & $1.77 \pm 0.39$ & 9.7 \\
\hline Gly. 0.1 & 4.7 & 4.03 & $1.08 \pm 0.16$ & 7.1 \\
\hline Pyr. 0.1 & 6.3 & 3.83 & $1.38 \pm 0.52$ & 8.6 \\
\hline Cou. 5m & 5.0 & 4.18 & $1.40 \pm 0.38$ & 6.6 \\
\hline Cit. 4 & 4.0 & 3.85 & $1.54 \pm 0.42$ & 8.9 \\
\hline Ce. $8 \mathrm{~m}$ & 6.3 & 3.92 & $1.64 \pm 0.45$ & 7.5 \\
\hline
\end{tabular}


Table 6. Average roughness of the chosen samples obtained by AFM

\begin{tabular}{|c|c|c|}
\hline Sample & $\begin{array}{c}\text { Average } \\
\text { Roughness Sa } \\
\text { (nm) }\end{array}$ & $\begin{array}{c}\text { Root mean } \\
\text { square } \\
\text { Sq (nm) }\end{array}$ \\
\hline $\begin{array}{c}\text { No } \\
\text { additives }\end{array}$ & 341 & 410 \\
\hline Sac. 2.5 & 343 & 407 \\
\hline Gly. 0.1 & 207 & 246 \\
\hline Pyr. 0.1 & 155 & 219 \\
\hline Cou. 5m & 310 & 383 \\
\hline Cit. 4 & 213 & 249 \\
\hline Ce. $8 \mathrm{~m}$ & 191 & 238 \\
\hline
\end{tabular}


Figures

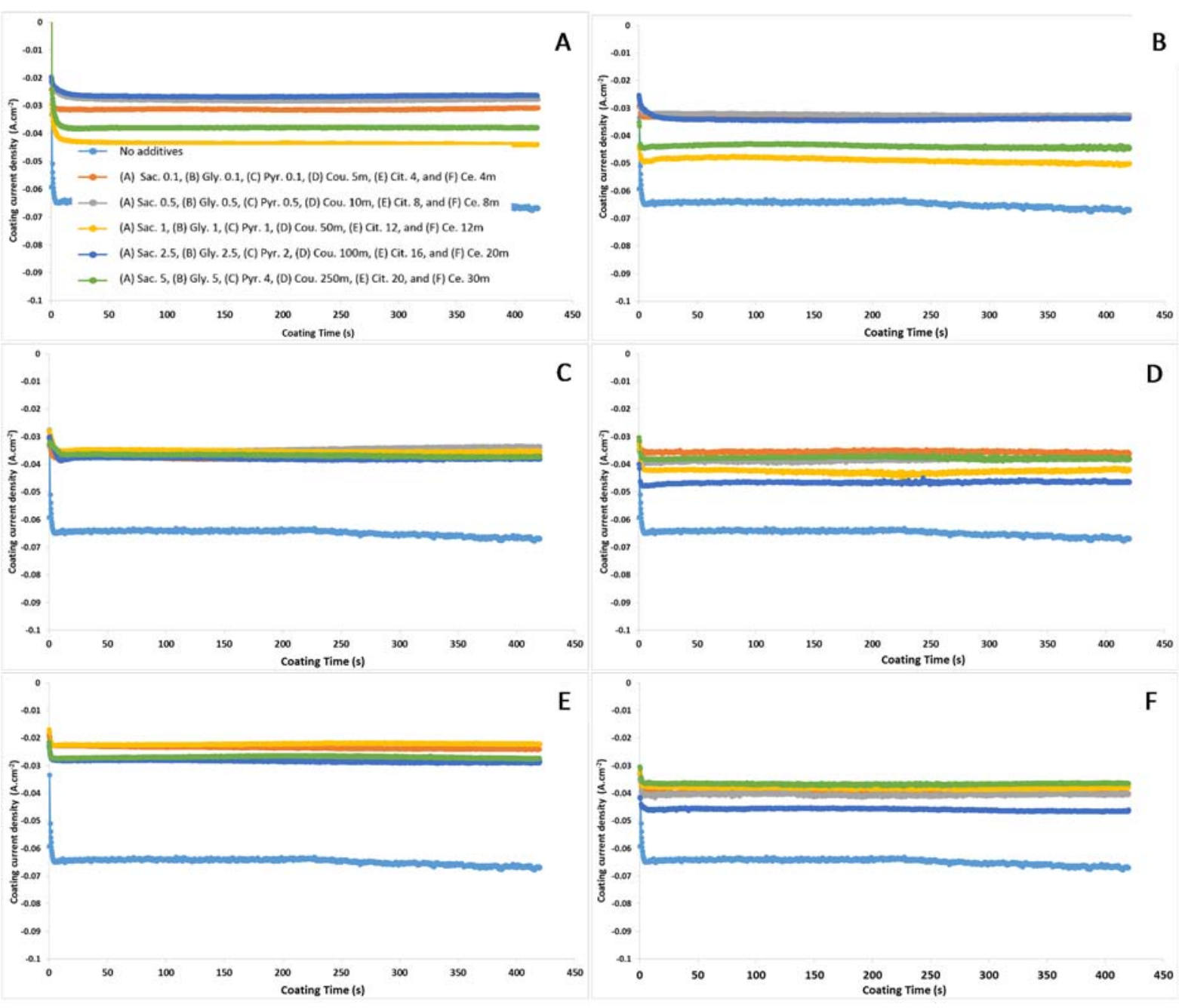

Figure 1. Current density-coating time curves for Ni-P coatings in the presence of (A) saccharine, (B) glycine, (C) PPS, (D) coumarin, (E) sodium citrate, and (F) cerium sulfate as additive. 


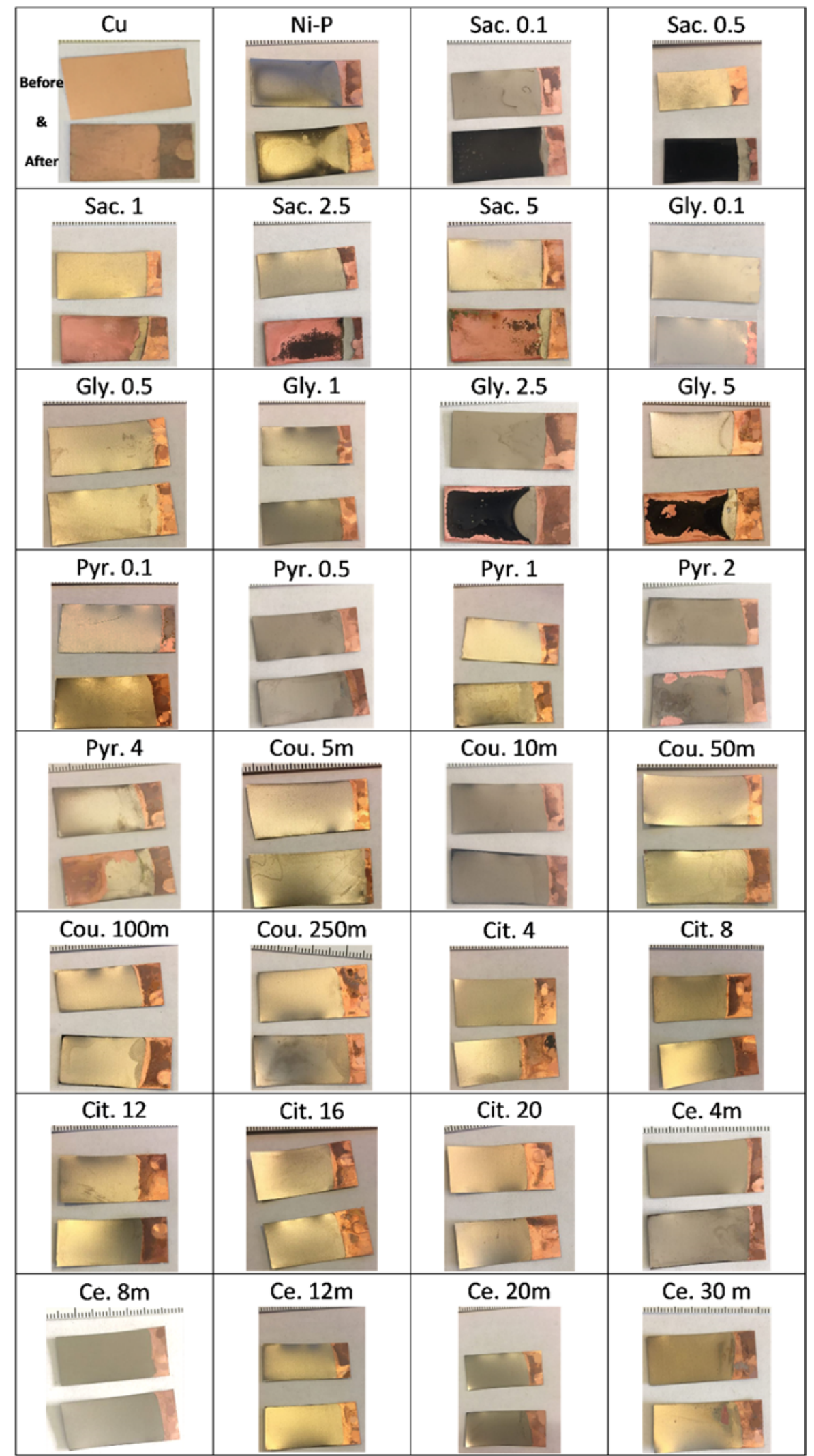

Figure 2. Coated samples before and after the corrosion tests. 


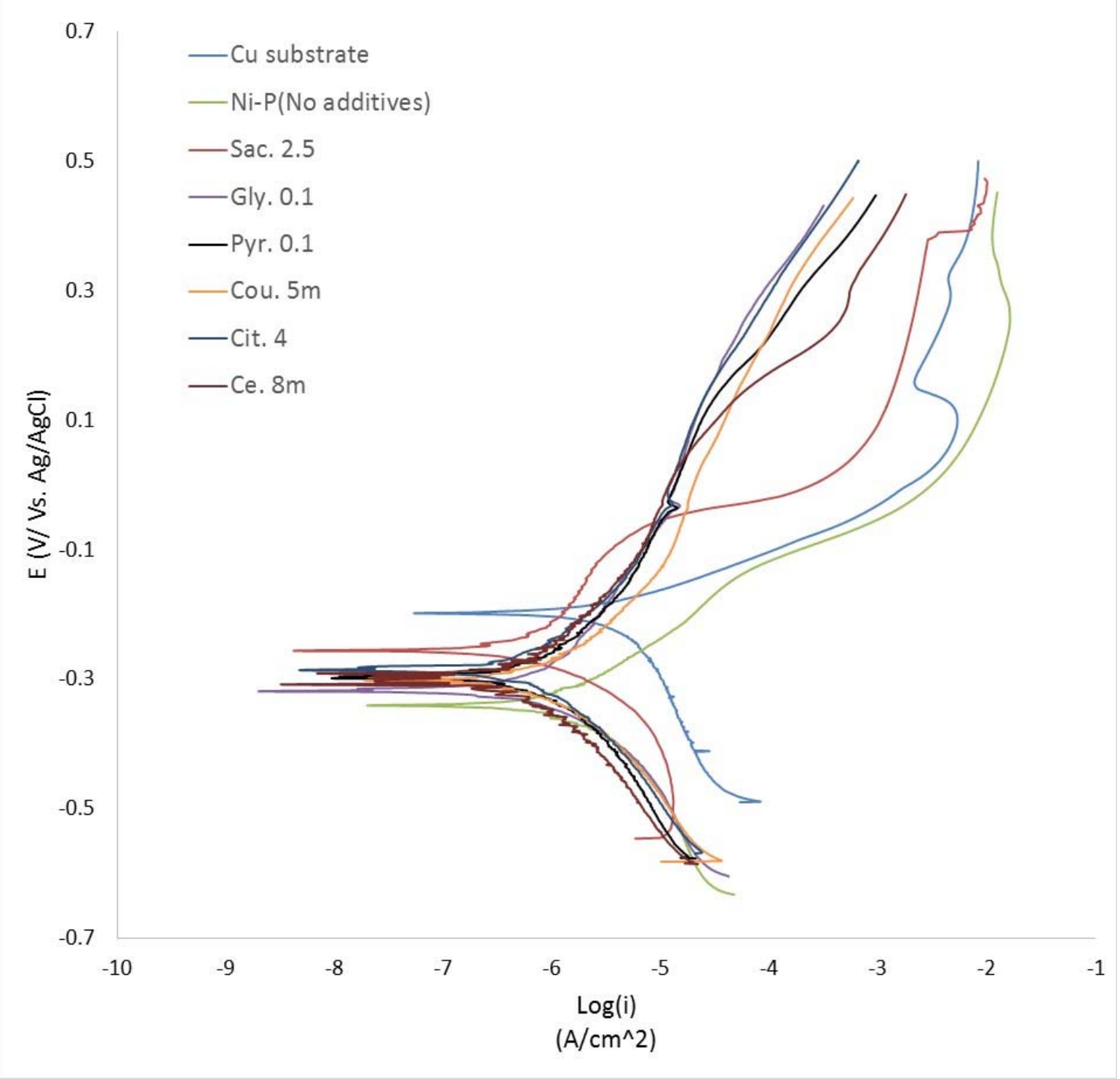

Figure 3. Potentiodynamic polarization curves for the substrate (Cu), Ni-P with no additives, Sac. 2.5, Gly. 0.1, Pyr. 0.1, Cou. 5m, Cit. 4, and Ce. $8 \mathrm{~m}$. 


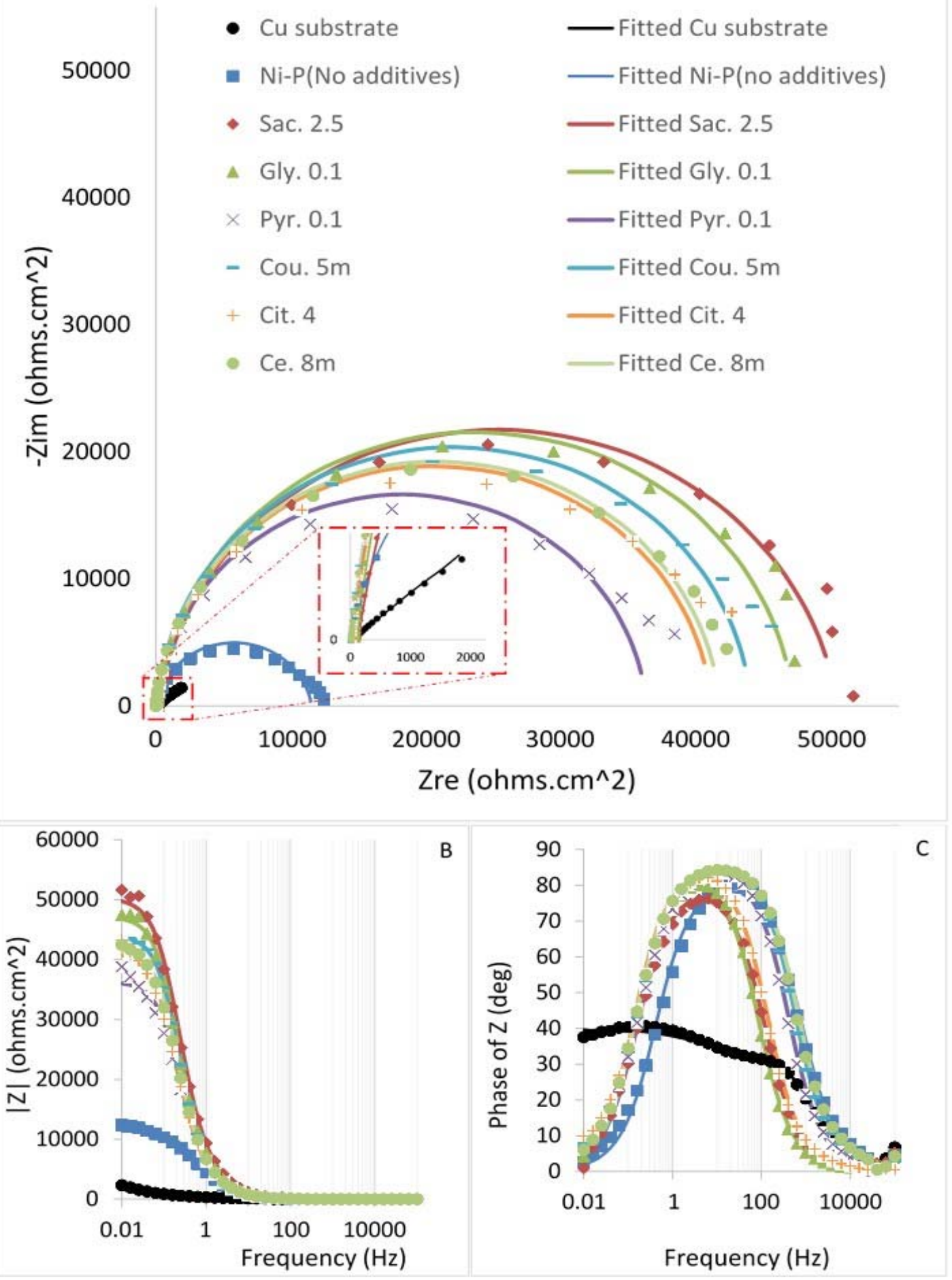

Figure 4. (a) Nyquist, (b) Bode-Z, and (c) Bode-Phase curves for the substrate $(\mathrm{Cu})$, Ni-P with no additives, Sac. 2.5, Gly. 0.1, Pyr. 0.1, Cou. 5m, Cit. 4, and Ce. $8 \mathrm{~m}$. 


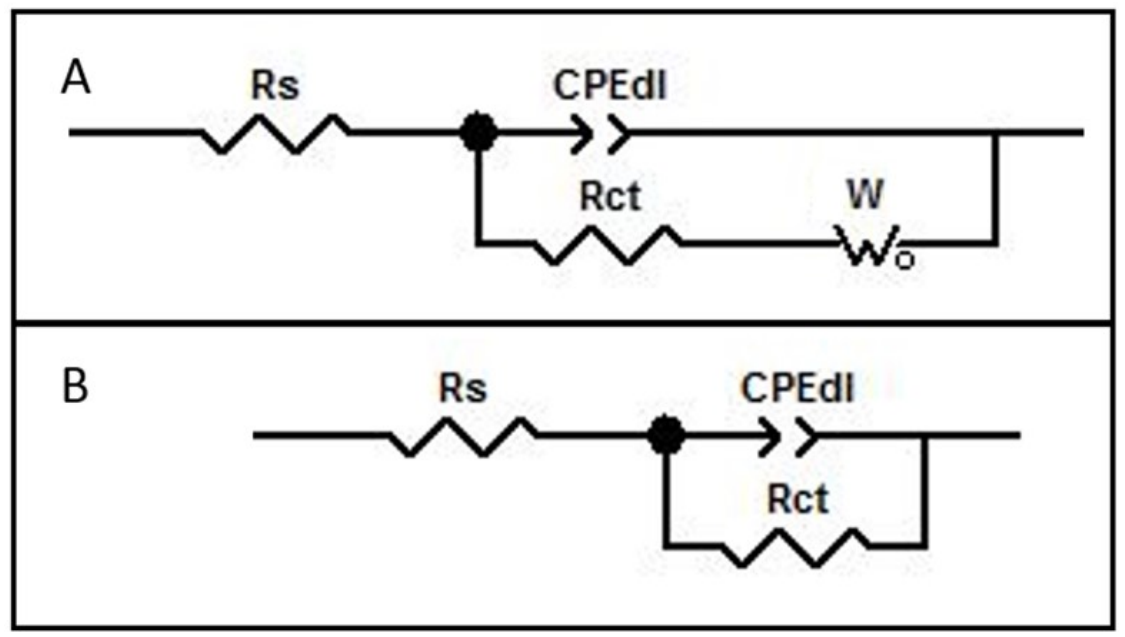

Figure 5. Proposed ECs for fitting the EIS data for (A) Cu substrate, and (B) $\mathrm{Ni}$-P coated samples with and without additives. 


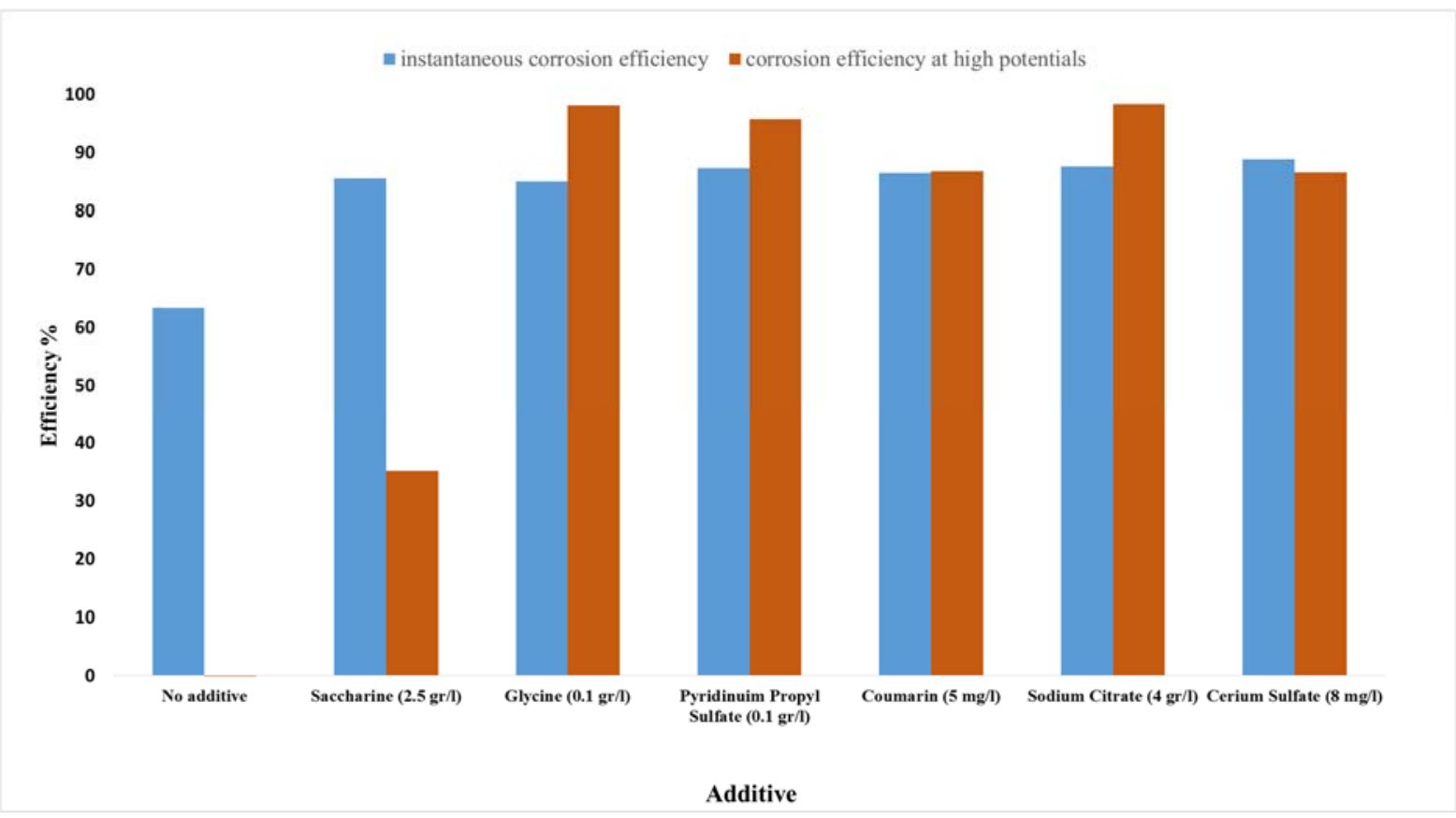

Figure 6. Corrosion efficiency, instantaneous and at high potentials, for Ni-P with no additives, Sac. 2.5, Gly. 0.1, Pyr. 0.1, Cou. 5m, Cit. 4, and Ce. $8 \mathrm{~m}$.

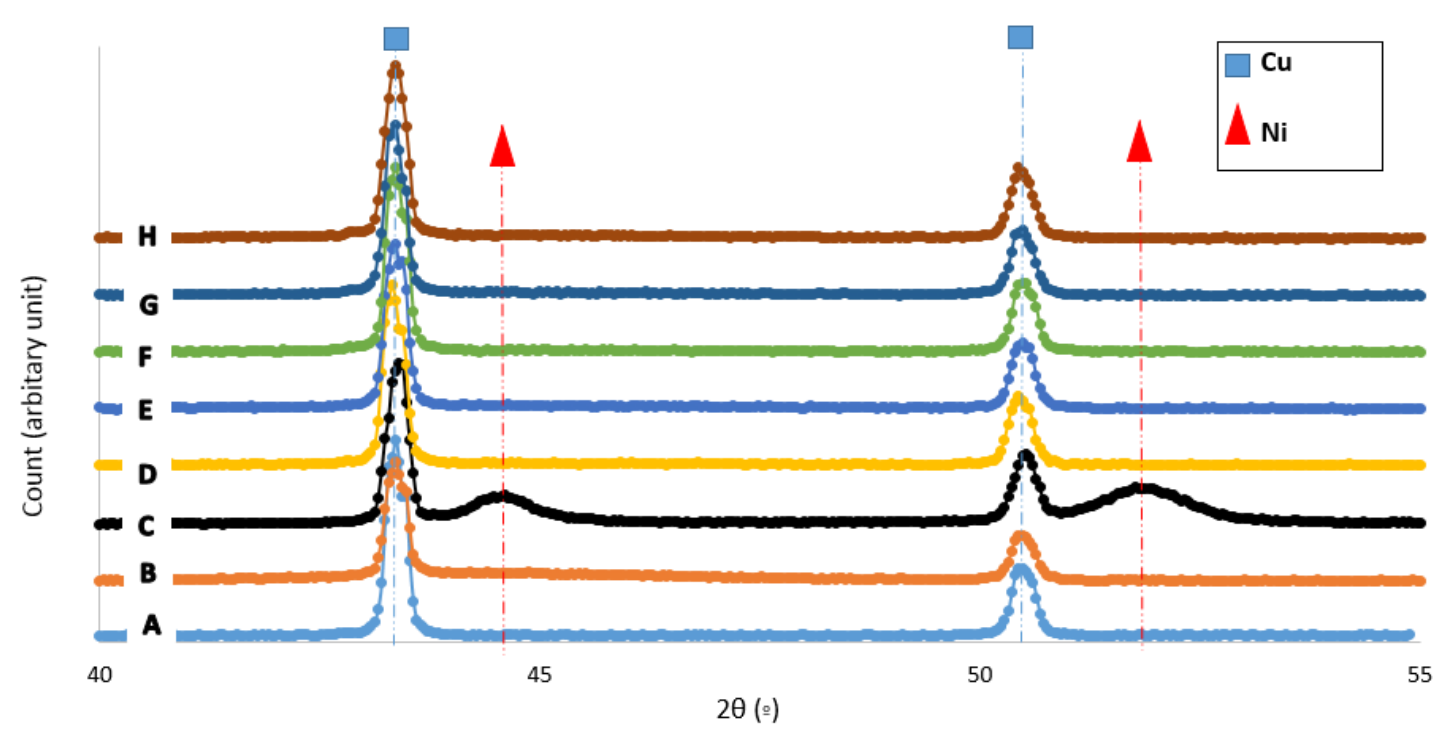

Figure 7. X-Ray diffraction patterns of (A) Cu substrate, (B) Ni-P coating without additives, (C) Sac. 2.5, (D) Gly. 0.1, (E) Pyr. 0.1, (F) Cou. 5m, (G) Cit. 4, and (H) Ce. $8 m$. 


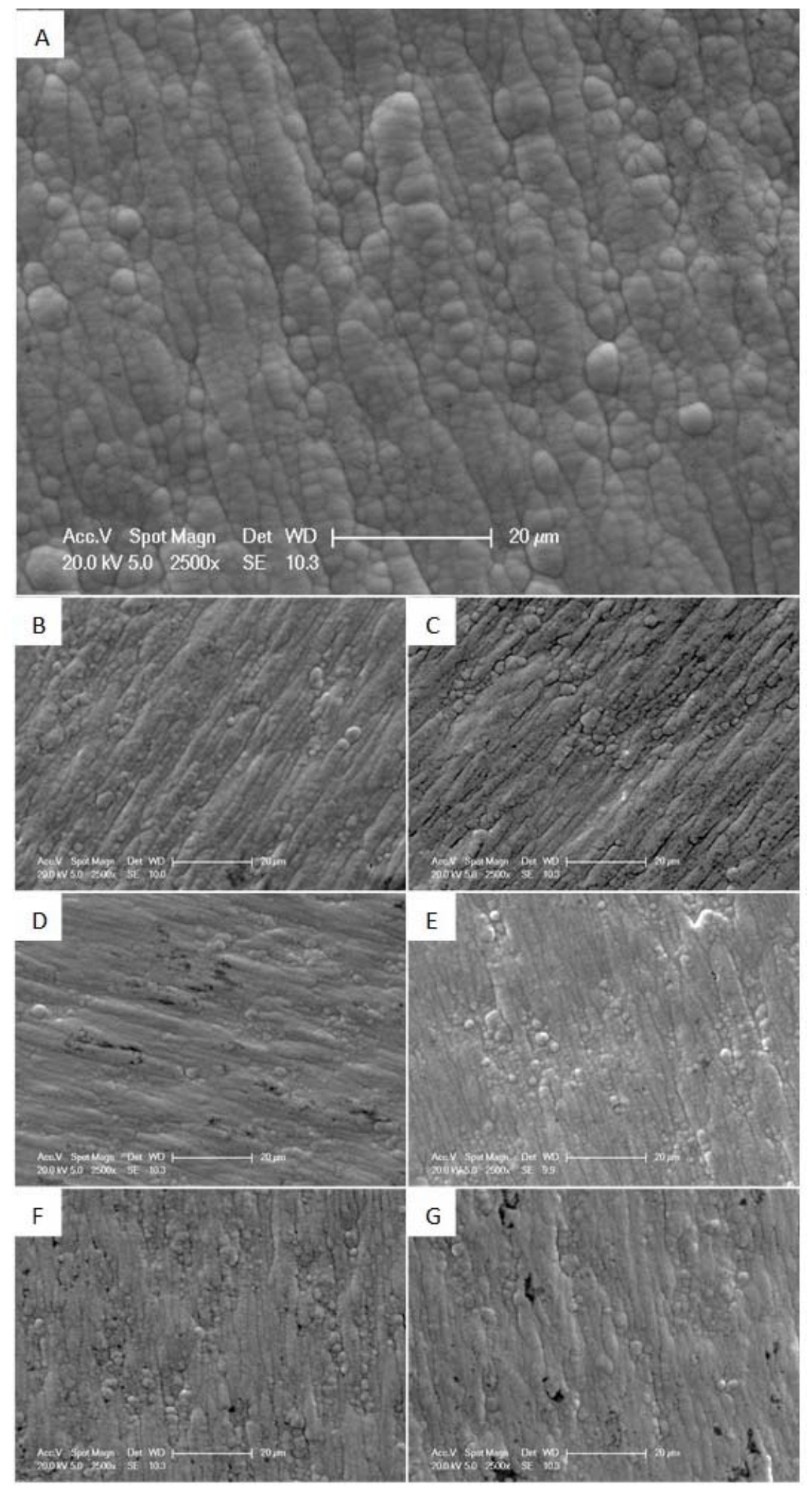

Figure 8. SEM images of (A) Ni-P without additives, (B) Sac. 2.5, (C) Gly. 0.1, (D) Pyr. 0.1, (E) Cou. 5m, (F) Cit. 4, and (G) Ce. $8 m$. 


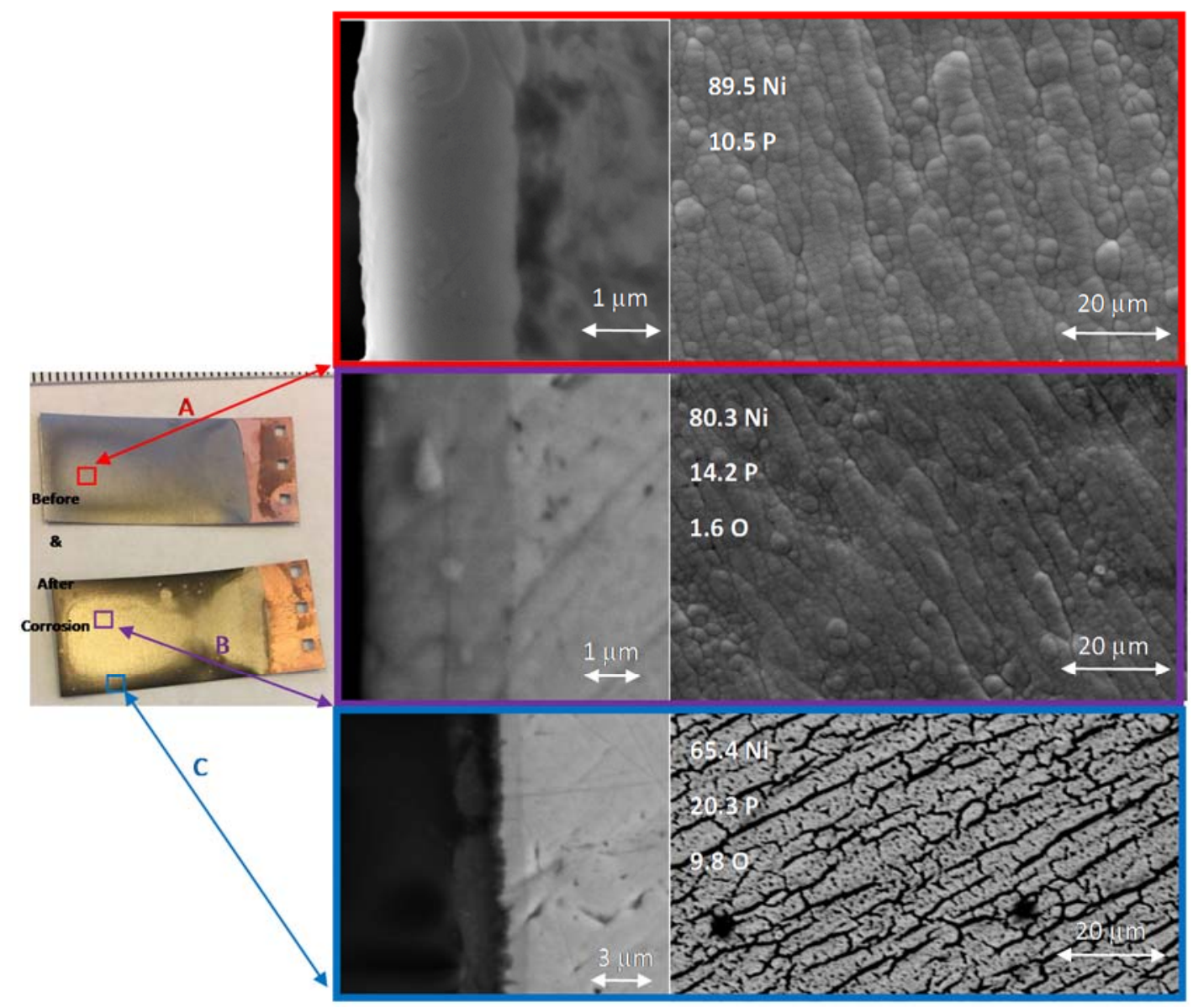

Figure 9. Cross-section and surface SEM images of Ni-P without additives, (A) before corrosion, $(B)$ shiny part after corrosion, and $(C)$ dark region after corrosion. 

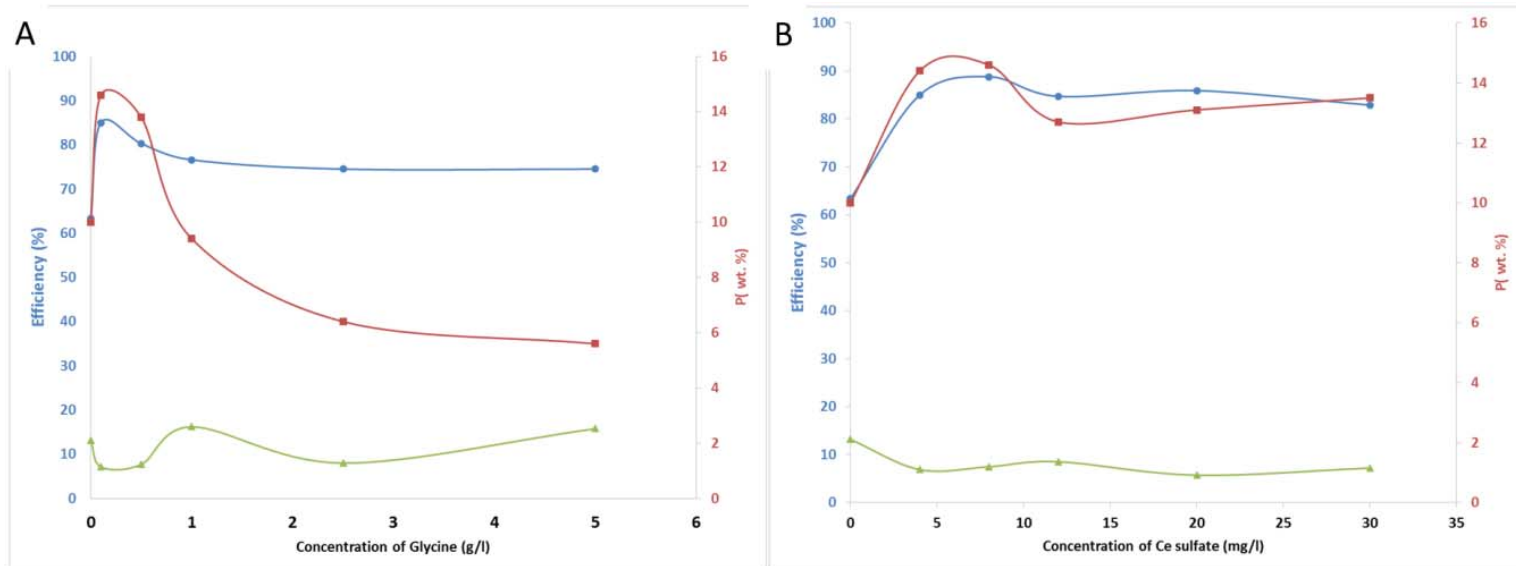

Figure 10. Effects of the concentration of glycine (A) and cerium sulfate (B) as additives on the corrosion efficiency $(\rightarrow)$, coating efficiency $(\rightarrow)$, and $P$ content $(\rightarrow)$ of Ni-P layers. 

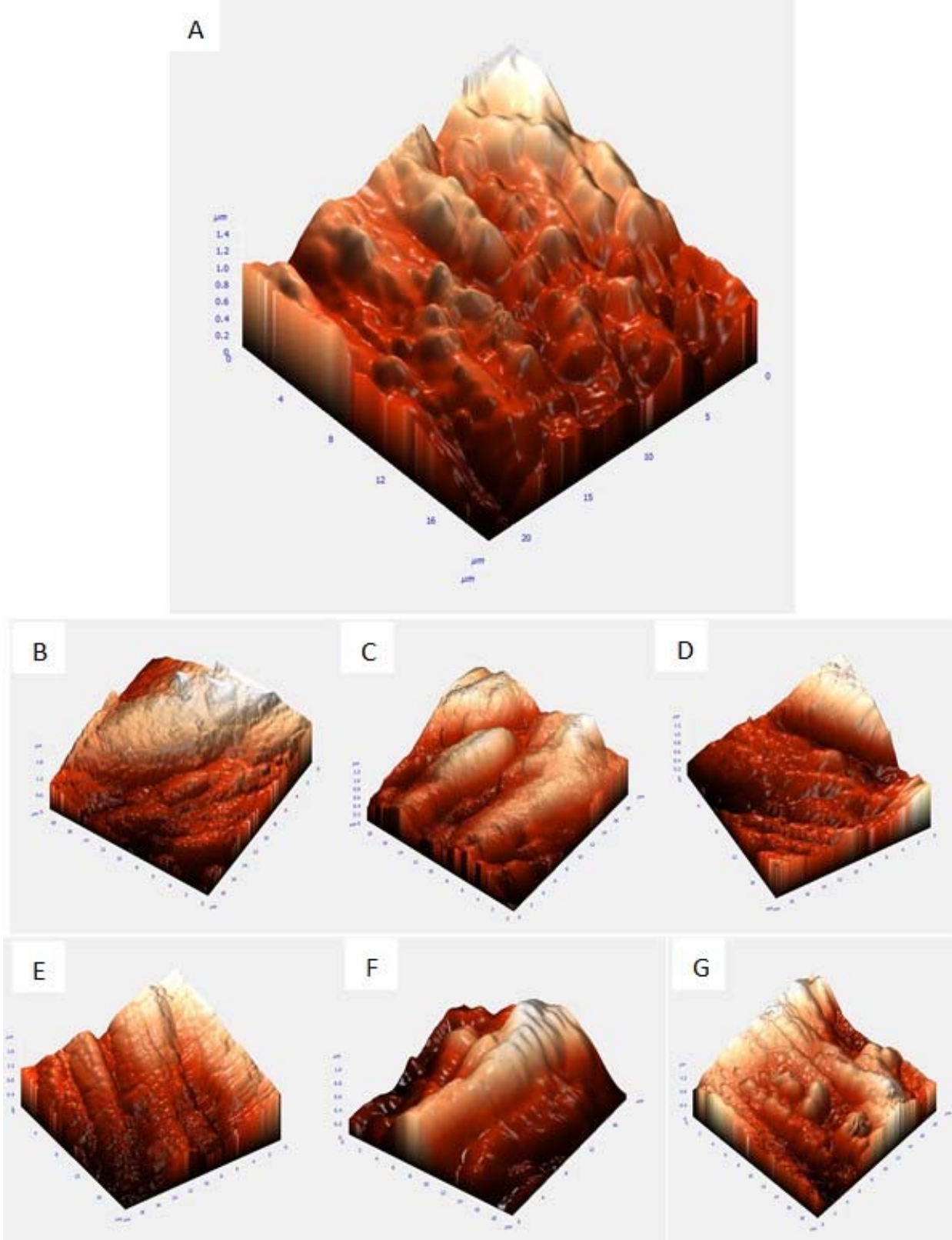

Figure 11. AFM images of (A) Ni-P without additives, (B) Sac. 2.5, (C) Gly. 0.1, (D) Pyr. 0.1, (E) Cou. 5m, (F) Cit. 4, and (G) Ce. $8 m$. 